\title{
La subjetividad en el lenguaje político del presidente Mujica: la construcción de su relato
}

\author{
Monique Marie Vaughan Moppett \\ Facultad de Comunicación, Universidad Austral
}

\section{Resumen}

Recibido: 26 de septiembre de 2014.

Aceptado: 15 de noviembre de 2014.

Este artículo describe un estudio de caso iniciado en 2012 sobre el discurso político del presidente Mujica que determinó su coherencia discursiva y su construcción del poder. La teoría de la enunciación, de Catherine Kerbrat-Orecchioni, fue aplicada a cinco discursos clave pronunciados por el presidente entre 1985 y 2011 y permitió examinar sus elecciones discursivas. Para este fin, se estableció una cronología de hechos históricos y se seleccionaron hitos en su biografía política. Una metodología general de análisis del discurso político requiere de un macroesquema teórico que determine sus límites, un esquema intermedio que categorice su contenido y un microesquema que examine los enunciados en su situación de comunicación. En esta investigación se identificó la necesidad de introducir otras herramientas metodológicas que enriquecieran los hallazgos y dieran mayor precisión al análisis del corpus. Para ello se recurrió a una triangulación metodológica que comprendiese los campos del análisis de discurso y la comunicación política, ya que la teoría de la enunciación resultaba insuficiente para esclarecer las inscripciones sociales del discurso y merecía reforzarse con los aportes de otros teóricos como Eliseo Verón y su caracterización del discurso político, y Mario Riorda y su concepto de mito de gobierno. Los hallazgos obtenidos a partir de la aplicación de esta triangulación estarían señalando un evidente vínculo entre el relato y la construcción del poder y justificarían la utilización del análisis casuístico para la investigación de otros corpora de discursos políticos.

Palabras clave: teoría de la enunciación, discurso político, análisis del discurso, mito de gobierno, subjetividad, estrategias discursivas.

\section{Subjectivity in the political language of president Mujica: the construction of his narrative}

\section{Abstract}

This article describes a case study initiated in 2012 on the political discourse of president Mujica, which determined his discursive coherence and construction of power. Catherine Kerbrat-Orecchioni's enunciation theory was applied to five key speeches delivered by the 
president between 1985 and 2011, and allowed a close examination of his discursive strategies. To this end, a chronology of historical events was established and milestones in his political biography were selected. A general methodology for the analysis of political discourse requires a macro-level theory to define its limits, a mid-level theory to categorize its contents, and a micro-level theory to examine utterances produced in the communicative situation. The need for introducing other methodological tools was identified so as to enrich findings and ensure the accuracy of corpus analysis. Thus, a methodological triangulation was applied encompassing the fields of discourse analysis and political communication, since enunciation theory was insufficient to elucidate the social inscriptions of discourse and merited reinforcement with the contributions of other theorists, such as Eliseo Verón and his characterisation of political discourse, and Mario Riorda and his concept of government myth. The findings obtained from the application of this triangulation would be indicating a clear link between narrative and the construction of power, and justifies the use of the case study method for research of other political discourse corpora.

Keywords: enunciation theory, political discourse, discourse analysis, government myth, subjectivity, discursive strategies.

\section{A subjetividade na linguagem política do presidente Mujica: a construção de seu relato}

\section{Resumo}

Esse artigo descreve um estudo de caso iniciado no ano 2012 sobre o discurso político do presidente Mujica que determinou sua coerência discursiva e sua construção do poder. A teoria da enunciação de Catherine Kerbrat-Orecchioni, foi aplicada a cinco discursos chave, pronunciados pelo presidente entre os anos 1985 e 2011 e permitiu examinar suas eleições discursivas. Para esse fim, foi estabelecida uma cronologia de fatos históricos e foram selecionados marcos em sua biografia política. Uma metodologia geral de análise do discurso político requere de um macroesquema teórico para determinar seus limites, um esquema intermédio para categorizar seu conteúdo e um microesquema para examinar os enunciados em sua situação de comunicação. Nesta pesquisa foi identificada a necessidade de introduzir outras ferramentas metodológicas para enriquecer os achados e para dar maior precisão à análise do corpus. Para isso, se recorreu a uma triangulação metodológica que compreendesse os campos da análise de discurso e a comunicação política, já que a teoria da enunciação resultava insuficiente para esclarecer as inscrições sociais do discurso e merecia ser reforçada com as contribuicoes de outros teóricos como Eliseo Verón e sua caracterização do discurso político, e Mario Riorda e sua noção de mito de governo. Os achados obtidos a partir da aplicação desta triangulação estariam sinalando um evidente vínculo entre o relato e a construção do poder e justificariam a utilização da análise casuística para a pesquisa de outros corpora de discursos políticos.

Palavras chave: teoria da enunciação, discurso político, análise do discurso, mito de governo, subjetividade, estratégias discursivas. 
El discurso no es simplemente aquello que traduce las luchas o los sistemas de dominación, sino aquello por lo que, y por medio de lo cual se lucha, aquel poder del que quiere uno adueñarse.

Michel Foucault, lección inaugural en el Collège de France, 1970.

\section{Introducción}

El propósito de esta investigación iniciada en 2012 fue examinar qué alcances teóricos y metodológicos válidos podría aportar la lingüística al análisis del discurso político en Uruguay. Este enfoque se inscribe dentro de las nuevas tendencias de investigaciones en América Latina sobre comunicación política que parecieran evidenciar un lento desplazamiento desde el clásico estudio de las agrupaciones políticas hacia una mayor exploración de los elementos que configuran la cosmovisión y el perfil de sus dirigentes.

La aparición de José Alberto Mujica Cordano como singular personaje político dentro de un ambiente social conservador en Uruguay es, de por sí, un hecho remarcable. No solo habla como un uruguayo más, sino que la exhibición de la empatía de una persona sencilla y humilde le da un carácter masivo a su campo discursivo al demostrar que entiende a la gente común, se identifica con ella, piensa como ella y vive como ella. La relevancia que su lenguaje tiene para un aporte lingüístico al análisis del discurso político uruguayo lo convirtió en el tema ineludible para intentar un estudio de caso en profundidad. Por otro lado, el interés fue potenciado por el incipiente estado del arte del análisis del discurso en Uruguay, ya que la mayoría de las escasas investigaciones existentes provienen de la historia ${ }^{1}$, la ciencia política ${ }^{2}$ y la sociología como disciplinas interpretativas.

La estructura del presente artículo contiene el marco teórico y conceptual elegido, el análisis y la interpretación de los datos coleccionados y el desarrollo de una metodología de triangulación para el estudio del corpus. Las conclusiones son preliminares por tratarse de un trabajo de investigación en curso.

\footnotetext{
1 Véase la contribución de Aldo Marchesi sobre los caminos culturales del consenso autoritario durante la dictadura en Demasi et al. (2009, p. 325-398).

2 Véase el análisis discursivo que realiza Francisco Panizza (1990, p. 126-197) desde el enfoque de la ciencia política.
} 


\section{Marco teórico y conceptual}

El modelo analítico elegido se inscribe dentro del marco de la teoría de la enunciación (Kerbrat-Orecchioni, 1980). El semiólogo francés Emile Benveniste (1977, p. 83) define a la enunciación como "la puesta en funcionamiento de la lengua por un

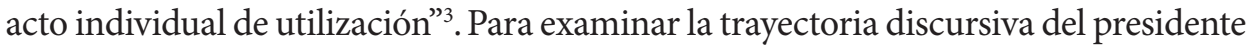
Mujica se seleccionaron hitos en su biografía política. La hipótesis de la que partió la investigación fue, por un lado, que el relato que dio forma a la imagen pública del presidente a lo largo del tiempo fue creada por él mismo y que instrumentalmente utilizó los medios de comunicación como vehículo para interpretar a la sociedad uruguaya en forma distinta de sus predecesores; y, por el otro, que tal interpretación resaltó el ethos ${ }^{4}$ uruguayo con sus rasgos, atributos y comportamientos. Conceptualmente, esta construcción de la identidad interesa por el lazo que tiene el ethos con la reflexividad enunciativa. Según Dominique Maingueneau (2002): "la eficacia del ethos depende del hecho de que envuelve de algún modo la enunciación sin ser explicitado en el enunciado" (p. 56). Si el análisis de la enunciación/enunciado concibe al lenguaje como marcado subjetivamente, era plausible entonces estudiar esta subjetividad lingüística en el lenguaje político de Mujica. A tales efectos, se seleccionaron cinco de sus discursos clave, que corresponden a cada uno de los hitos sociohistóricos que se consideran más relevantes en la línea del tiempo comprendida entre los años 1985 y 2011, ya que cada hito corresponde al comienzo de una nueva etapa de construcción de su poder político: dos durante su período militante, uno durante la campaña electoral por la presidencia, su discurso oficial de asunción del mando y un discurso posterior dirigido a importantes empresarios de países miembros del Mercosur.

Los alcances teóricos del estudio debieron necesariamente incluir la evolución histórica del presidente, tanto por sus dimensiones sociológicas y etnográficas, como por la formación de su personal ideología dentro de la variedad doctrinaria de la izquierda uruguaya. Las competencias lingüísticas y paralingüísticas que posee el presidente constituyen además elementos sustantivos por cuanto hacen referencia a su educación formal y explican su habilidad retórica para codificar y descodificar mensajes. Asimismo, fue fundamental para este trabajo entender sus orígenes familiares, los condicionamientos económicos que tuvo en su vida y las actitudes interpretativas y evaluativas que lo llevaron a abrazar el pensamiento socialista a pesar de

\footnotetext{
3 Véase la obra de Benveniste $(1971,1977)$ para una descripción formal del aparato de enunciación, anterior al desarrollado por Kerbrat-Orecchioni.

4 Categoría que permite reflexionar en los procesos sobre los cuales el discurso puede provocar adhesiones.
} 
haberse iniciado políticamente dentro del ideario conservador del Partido Nacional a los veintiún años y su definitiva adscripción revolucionaria dentro del Movimiento de Liberación Nacional-Tupamaros (MLN-T) a los veintinueve ${ }^{5}$.

Para la revisión de la trayectoria discursiva del presidente se utilizaron conceptos de análisis del discurso inspirados en la perspectiva francesa; la que a su vez fue influenciada por el psicoanálisis y el marxismo. Hay que destacar que varias perspectivas y corrientes de pensamiento han diferido - y aún lo siguen haciendo-, sobre los límites teóricos de la definición del análisis del discurso, tanto en términos metodológicos como terminológicos. Tal es el caso del Diccionario de análisis del discurso de Patrick Charaudeau y Dominique Maingueneau (2005) donde lo califican como "una disciplina situada en un punto de cruce: el discurso integra por un lado dimensiones sociológicas, psicológicas, antropológicas [...] y por el otro se encuentra en el corazón mismo de estas disciplinas [...] Lo cual plantea además complejos problemas de relación con estos otros campos que trabajan sobre el discurso, de modo que la cuestión de las fronteras - o de la ausencia de fronteras- es fuente de continuas discusiones" (p. ix). Así es como Maingueneau distingue el análisis del discurso de primera generación de finales de los años sesenta y principios de los setenta, que buscaba resaltar las particularidades de las formaciones discursivas (discurso comunista, socialista, etc.) considerados como espacios relativamente autárquicos que se estudiaban a partir de su vocabulario, y el análisis del discurso de segunda generación ligado a las teorías enunciativas (que incluían problemas como el mecanismo de la enunciación, la heterogeneidad enunciativa y la polifonía, la paráfrasis y la reformulación, los géneros discursivos, la presuposición, los conectores de argumentación y el análisis léxico del discurso). Otros autores de referencia de esta segunda generación son Oswald Ducrot y Catherine Kerbrat-Orecchioni.

Sin embargo, la mayoría de estas perspectivas comparten algunos presupuestos básicos acerca de la definición del objeto discurso, como la articulación compleja de un espacio lingüístico o textual con las condiciones extralingüísticas que la hicieron nacer. Esto significa que es imposible realizar un análisis discursivo de un texto sin analizar su contexto, concepto en sí mismo endeble y que solo puede definirse en función de los objetivos - ya elegidos para esta investigación- desde el punto de vista de las distintas ciencias sociales que intervienen en ella. Por cuanto este es el verdadero desafío epistemológico y metodológico que plantea el análisis del discur-

\footnotetext{
Para una detallada biografía y formación del ideario de Mujica véase Campodónico (2005), Blixen (2009), Israel (2014), Mazzeo (2002), Pernas (2013) y Rabuffetti (2014).
} 
so, la investigación examinó cinco discursos clave del presidente dentro del contexto histórico e ideológico en que fueron realizados. Es decir que se trató de construir un objeto de estudio cuya materialidad lingüística no borrara su materialidad sociohistórica y de definir una metodología que no privilegiara un aspecto sobre el otro.

Este marco teórico deja atrás el tradicional enfoque de la lingüística estructural y generativa para indagar más acerca de la relevancia de la pragmática en las ciencias del lenguaje. En consecuencia, el análisis del discurso toma de la lingüística descriptiva una interpretación más abarcadora del mundo real en que se desenvuelve el sujeto hablante y en el que se realizan las instancias interverbales a través de otras competencias, además de las lingüísticas. Este enfoque pragmático es relevante, ya que sostiene que el lenguaje no es un objeto que se pueda estudiar en forma aislada de otras dimensiones de la vida social. Por ello debe contemplar un escenario más amplio que tome en cuenta todos los parámetros de la interacción verbal y las varias competencias que se requieren de los interlocutores para lograr la comunicación. De ahí el particular interés por el enfoque de Kerbrat-Orecchioni que busca determinar el alcance y el dominio de aplicación de la enunciación en el campo de una nueva lingüística alejada de los tradicionales campos del mensaje y el código, y que toma en cuenta estos otros parámetros de la situación comunicacional. Su enfoque lo esquematiza en la figura 1.

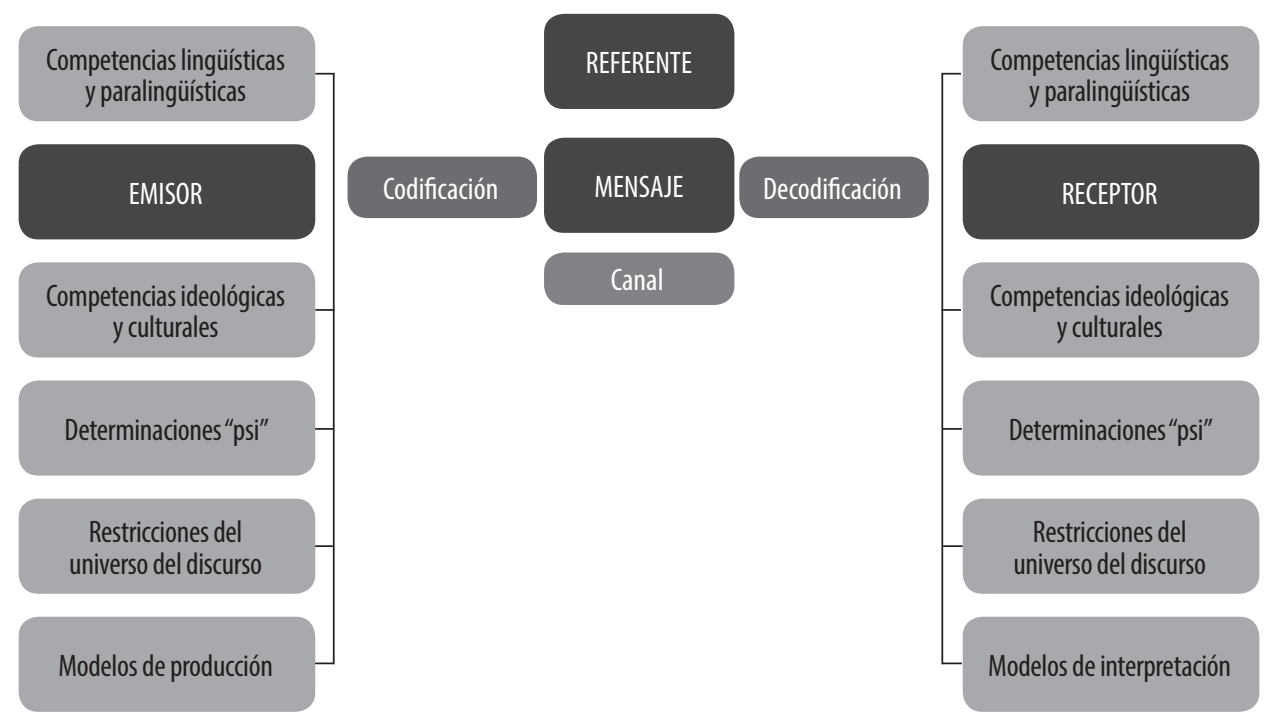

Figura 1. Marco enunciativo de Kerbrat-Orecchioni. 
En su obra La enunciación: de la subjetividad en el lenguaje", la autora realiza una revisión del modelo de comunicación de Roman Jakobson, al que critica junto con otros autores, por connotar una comunicación ideal, total, transparente y libre de fallas, que se da entre dos individuos "que poseen el mismo código". Asimismo cuestiona los postulados de Ferdinand de Saussure y Noam Chomsky sobre un código único y monolítico argumentando que los sujetos hablantes-oyentes poseen diferentes lectos - "dialectos, sociolectos e idiolectos" - y le quita validez a la teoría de que existe un código universal compartido por todos los hablantes, ya que ignora los hechos naturales y variaciones dentro de los intercambios lingüísticos (KerbratOrecchioni, 1980, p. 11). En este sentido, según la autora, la intercomprensión parcial es un resultado natural de la comunicación. Su modelo revisado ilustra la dinámica del intercambio verbal, la intersección de las competencias lingüísticas y extralingüísticas de los interlocutores, las negociaciones y codificaciones/descodificaciones de los enunciadores que van transformando el discurso a medida que se desarrolla, culminando así en una intercomprensión parcial y no una comunicación ideal y perfecta tal como se propuso en los tradicionales modelos lingüísticos.

En el campo de investigación que explora, la autora añade dimensiones sociológicas, ideológicas, psicológicas y lógicas que dejan marcas inteligibles en el discurso. En coherencia con esta nueva corriente lingüística, que tiende hacia el pragmatismo y toma la palabra como medio de acción, ella introduce la noción de "producción" en su modelo revisionista. Entre los nuevos parámetros que influyen en el modelo figuran las competencias lingüísticas, paralingüísticas, ideológicas y culturales, y las determinaciones psicológicas, entre otros.

\section{Metodología utilizada}

\subsection{Triangulación metodológica}

La investigación se apoyó en una triangulación metodológica ${ }^{6}$ de elaboración propia $^{7}$ para examinar con mayor precisión las múltiples dimensiones del objeto de estudio (el campo enunciativo que engloba los cinco discursos del presidente Mujica) y tuvo como propósito enriquecer el análisis y disminuir los sesgos en la interpretación de los datos. En esa triangulación se utilizaron, además, otros principios

\footnotetext{
6 Véase Rodríguez Ruiz, O. (2005). La triangulación como estrategia de investigación en ciencias sociales. Revista de investigación en gestión de la innovación y tecnología, no. 31. Disponible en: http://www.madrimasd.org/revista/ revista31/tribuna/tribuna2.asp (consulta: 25 sep. 2014).

7 Estructura de convergencia y complementariedades entre las teorías de Kerbrat-Orechioni, Riorda y Verón.
} 
definidos por dos aproximaciones teóricas distintas a las de Kerbrat-Orecchioni, provenientes de las teorías del discurso y de la comunicación. Por un lado, sobre la caracterización del discurso político, se incorporaron las propuestas de Eliseo Verón (1987, p. 13-15) - luego interpretadas por María Marta García Negroni y Mónica Graciela Zoppi Fontana (1992, p. 7-19) - para entender la construcción del campo discursivo como la intersección de varios enunciados y la puesta en práctica de estrategias por el enunciador discursivo para construir una imagen propia. Además, como esta construcción de identidad propia también la trata un teórico de la comunicación política como lo es Mario Riorda, se incorporó su interpretación de la política basada en el mito de gobierno ${ }^{8}$ como un sistema de creencias coherente y completo. Se interpreta que esta noción del "mito" en Riorda se asemeja a la noción de "núcleo invariante" de Verón (1987, p. 14), por cuanto ambos aluden a un epicentro de valores y creencias que es constante en el tiempo y es coherente en su composición; es decir a un modelo simbólico de comunicar los ideales compartidos en un "nosotros político" o un "nosotros inclusivo" tal como lo define Kerbrat-Orecchioni (1980, p. 52-53). Además se intuye que también la subjetividad cumple un papel fundamental en la interpretación de este epicentro de valores y creencias.

De esta manera, al articular complementariedades entre las teorías de KerbratOrecchioni, Verón y Riorda, se hizo técnicamente posible analizar la verosimilitud del relato de Mujica en su construcción de una realidad común mediante grandes ideales, principios y valores que crean un marco de pertenencia cultural y logran instituir un mito movilizador. Al implementar articuladamente estos enfoques, se incrementó la objetividad de los hallazgos sobre el campo discursivo de Mujica y se obtuvo una visión alternativa de los datos para ampliar las conclusiones preliminares. En particular, se comprueba la eficacia de esta triangulación en el análisis molecular de comparación de frecuencias de la subjetividad (matriz Kerbrat-Orecchioni) y en el análisis de los múltiples destinatarios que utilizaron deícticos pronominales, descritos unos por Verón y clasificados otros por Kerbrat-Orecchioni.

\subsection{El corpus}

El corpus seleccionado estuvo compuesto por tres discursos de Mujica, previamente disponibles en formato de texto, y otros dos transcritos de una video-

\footnotetext{
8 Véase el blog Poder comunicar de Mario Riorda. Disponible en: http://marioriorda.com/blog/?p=248 (consulta: 25 sep. 2014).
} 
conferencia y de una grabación magnetofónica. El corpus contiene los siguientes discursos ${ }^{9}$ :

17 de marzo de 1985: discurso pronunciado en el Platense Patín Club, 48 horas después de la liberación de Mujica de la cárcel.

19 de diciembre de 1987: discurso en la IV Convención del MLN-T en el Estadio Franzini.

3 de junio de 2009: video del discurso de campaña presidencial del senador Mujica en Rio Branco, Departamento de Cerro Largo.

$1^{\circ}$ de marzo de 2010: discurso de asunción presidencial.

2 de abril del 2011: grabación magnetofónica del discurso del presidente en el almuerzo empresarial del Hotel Conrad en Punta del Este.

El corpus seleccionado ofreció una mirada integral del campo discursivo en el cual el presidente desarrolló su cosmovisión (convicciones y valores) y asumió posturas teóricas independientes de paradigmas anteriormente dominantes. A partir del marco de la enunciación de Kerbrat-Orecchioni y del campo discursivo y estrategias de Verón para identificar el cambio de paradigma que introdujo Mujica en la construcción de su relato, se tomaron en cuenta su prototeoría (Zanotti, 2005, p. 106) y núcleo invariante de valores, erguidos dentro de un campo simbólico que surge de la noción de mito de Riorda. A través de estos cinco discursos se estudiaron las negociaciones que Mujica dio en el espacio discursivo (enfrentamiento y persuasión), la evolución de su prototeoría evidenciada en cada paradigma en los cinco estadios que cambia la forma y no el eje, y cuyo valor centrípeto es la búsqueda de la transformación de la conciencia humana.

\subsection{Criterios de calidad ${ }^{10}$}

Con el propósito de aportar un enfoque metodológico adicional al estudio de la política uruguaya, se intentó cumplir con ciertos criterios de calidad de diseño, particularmente de seguridad, credibilidad y generalidad. En lo que concierne al criterio de la seguridad, se seleccionaron discursos correspondientes a cada uno de los hitos sociohistóricos más relevantes entre 1985 y 2011, por cuanto cada hito corresponde al inicio de una nueva etapa de construcción del poder político de

\footnotetext{
9 Se codificaron del siguiente modo: primer discurso (D1, 1985), segundo discurso (D2, 1987), tercer discurso (D3, 2009), cuarto discurso $(\mathrm{D} 4,2010)$ y quinto discurso $(\mathrm{D} 5,2011)$.

10 Por tratarse de una investigación cualitativa, resultó necesario asegurar la calidad en el proceso de la investigación con los criterios del libro Estrategias de investigación cualitativa, coordinado por Irene Vasilachis de Gialdino (2006, p. 90-97).
} 
Mujica, lo cual resguarda de la crítica de aleatoriedad al obtener datos objetivos. En cuanto al criterio de credibilidad, se proporcionó una descripción detallada, densa y completa que permitió formar categorías conceptuales y dimensiones del relato del presidente. Finalmente, en cuanto al criterio de generalidad, se trató de garantizar la replicabilidad de la herramienta para el estudio del lenguaje de otros actores políticos uruguayos, por tratarse de un método para interpretar las categorizaciones que realiza el discurso político.

\section{Análisis de los datos}

El procedimiento consistió en estudiar los mecanismos enunciativos utilizados por el presidente para la construcción de un relato con identidad propia, es decir de cómo se generó ese relato, a qué fuentes de legitimidad acudió para nutrirlo (los valores y experiencias de su vida), cómo progresó, cómo se modificó o se adaptó en el tiempo y cómo mantuvo su coherencia interna. Para ello se utilizaron las manifestaciones de la subjetividad presentes en el corpus de discursos pronunciados en distintas épocas de su carrera política; en una primera etapa, las marcas de la persona - quizás la huella más evidente de la presencia del sujeto en el discurso$y$, en una segunda etapa, los modos que tuvo (como locutor-autor) de referir la palabra ajena y sus diferentes actitudes frente a esas otras voces. Como resultado, el procedimiento produjo hallazgos de marcas de subjetividad en esos discursos e indicios de cómo esas marcas se correlacionan con la configuración de un ethos discursivo homogéneo en cuanto a su núcleo invariante de valores.

Asimismo, las habilidades de oratoria simbólica que despliega Mujica exigieron realizar un examen de las influencias lingüísticas que recibió la generación uruguaya de los años 60 provenientes de la cosmovisión revolucionaria de un Hombre Nuevo ${ }^{11}$ y de la fuerte tradición oral de la política uruguaya. Esa oralidad se extendió a su vez al lenguaje encubierto de los miembros del MLN-T ${ }^{12}$ en clandestinidad y al hábito de registrar los hechos en la memoria de sus miembros en lugar de documentos escritos o archivos; lo que parcialmente explica la ausencia de

\footnotetext{
11 Véase Guevara, E. (2007) y Guevara de la Serna, Ernesto (Che). El hombre nuevo. Proyecto Ensayo hispánico. Disponible en: http://www.ensayistas.org/antologia/XXA/Che/. (consulta: 25 sep. 2014).

12 Véase las entrevistas realizadas a diecisiete militantes y exmilitantes tupamaros por Clara Aldrighi (2009) para una representación del universo de opiniones y experiencias que conformaron el movimiento guerrillero.
} 
fuentes documentales originales para las investigaciones ${ }^{13}$. Finalmente se comprobó que todas estas influencias históricas y culturales se entrecruzaban permanentemente en el lenguaje que Mujica utilizó en los discursos analizados.

Estos hallazgos iniciales remitieron a una lectura más amplia de la bibliografía histórica y sociológica del Uruguay, particularmente a las líneas de pensamiento predominantes durante el siglo XX en que los dos partidos políticos tradicionales actuaron dentro de un mismo paradigma de poder como resultado del Pacto de la $\mathrm{Cruz}^{14}$ de 1897 y en el cual —porque conviene destacarlo para los propósitos de la investigación - el Partido Nacional salió perdiendo ${ }^{15}$. Es curioso observar, al menos, que Mujica haga referencia en sus discursos a su origen político blanco (marco histórico) y a la necesidad de un cambio de paradigma político hacia un futuro hombre nuevo o, si no fuera así, hacia un hombre mejor (marco ideológico).

Se intuye que esta búsqueda de un nuevo paradigma que alienta Mujica tiene su origen en un núcleo invariante ${ }^{16}$ de ideas y valores que posee desde hace tiempo, por una suerte de cosmovisión o Weltanschauung que gobierna su campo discursivo, y en un sistema de múltiples variaciones estratégicas que utiliza para ampliarlo y polemizar con el adversario de turno. Esquemáticamente, si se parte de tal núcleo invariante, las sucesivas etapas que utilizó fueron para conciliar y persuadir a unos y para enfrentar a otros enunciadores adversarios. Por lo tanto, cada hito correspondió al comienzo de una nueva etapa de construcción de su poder político (fig. 2), hitos que surgen claramente de su biografía y de su carrera política y que identifican los momentos en que supo ganar espacios de poder.

El primer hito es la liberación de los tupamaros el 17 de marzo de 1985 luego de 13 años de cautiverio y corresponde al discurso pronunciado días después de este hecho histórico ante la militancia tupamara (D1, 1985). El segundo hito es la decisión adoptada en 1987 por Mujica y sus partidarios de participar democráticamente en la vida política por las vías legítimas mediante la solicitud de ingreso

\footnotetext{
13 En palabras del propio Mujica: "porque los tupamaros fuimos presa de la urgencia. Muchas veces, queriéndolo hacer, no hicimos cosas fundamentales. [...] Tuvimos que olvidar la docencia, tuvimos que olvidarnos de escribir papeles, de escribir libritos; porque había cantones que evacuar, porque había que fabricar documentos, porque había que luchar con la clandestinidad (Discurso 2, 1987: 1.25-28). En el mismo discurso (D2, 1987) Mujica declara: "no luchamos por una sociedad para más dirigentes sino que estamos luchando por un hombre nuevo con capacidad de dirigirse (1.227). Los subrayados son del autor.

${ }_{14}$ El Pacto de la Cruz fue un acuerdo firmado el 18 de septiembre de 1897 entre el Partido Colorado y la dirección del Partido Nacional.

15 Sobre historia política de la izquierda uruguaya y de los partidos tradicionales véase Caetano (2011), Cultelli (2006), De Giorgi (2011), Garcé (2009), Labrousse (2009) y Rey Tristán (2006).

16 El concepto de núcleo invariante lo desarrolla Eliseo Verón (1987, p. 14-15).
} 
del MLN-Tupamaros al partido del Frente Amplio, decisión histórica dada a conocer en el discurso pronunciado en la IV Convención del MLN-Tupamaros (D2, 1987). El tercer hito es una arenga como Senador en 2009 captada en video, dirigida a poblaciones rurales del Departamento de Cerro Largo para que votaran en las elecciones por el Frente Amplio (D3, 2009). El cuarto hito es el discurso oficial de asunción presidencial del $1^{\circ}$ de marzo de 2010 (D4,2010). Por último, el quinto hito despliega la visión macroeconómica y social del mandatario en una reunión con empresarios nacionales y extranjeros realizada en 2011 en Punta del Este (D5, 2011).

A su vez, las estrategias discursivas que utilizó fueron las siguientes:

Estrategia de militancia (D1, 1985)

Estrategia de legitimación (D2, 1987)

Estrategia de apropiación (D3, 2009)

Estrategia de institucionalización interna (D4, 2010)

Estrategia de institucionalización externa (D5, 2011)

En el primer discurso del corpus $(D 1,1985)$ Mujica emplea una estrategia de militancia ante tupamaros y simpatizantes. Se advierten las convicciones de un viejo luchador que acaba de salir de la cárcel y quiere reinsertarse en la vida pública y

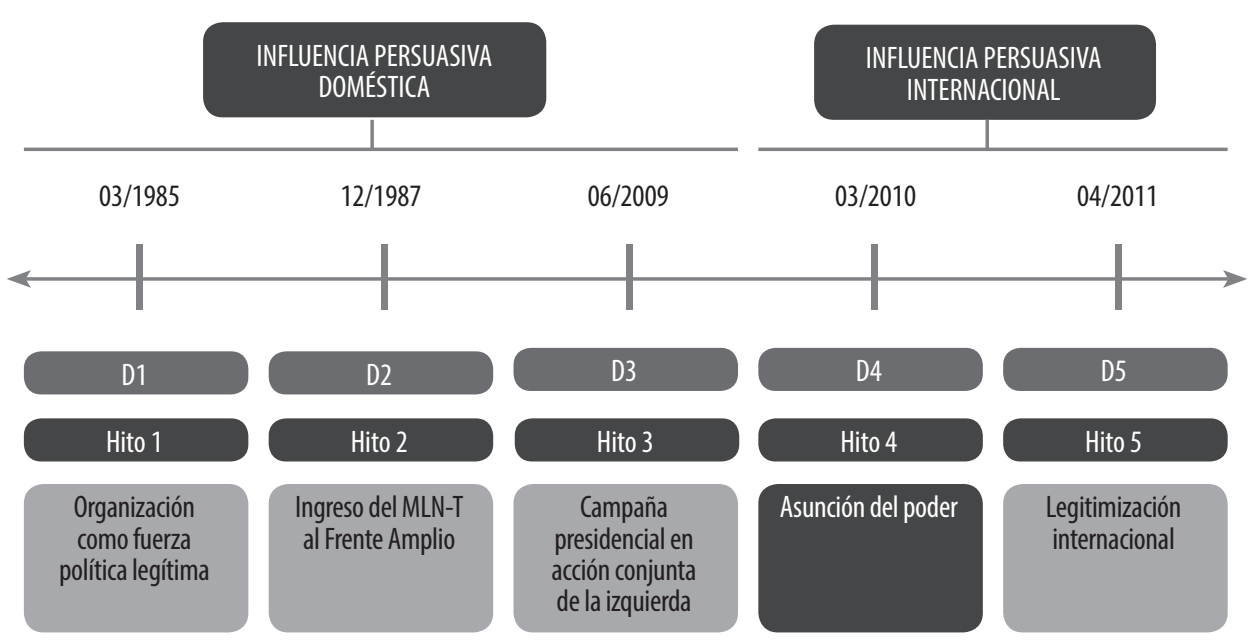

Figura 2. Hitos y cronología histórica de hechos. 
cuyo discurso se dirige hacia una fuerza política juvenil que necesita organizarse. Como orador, apela estratégicamente a la lealtad de la militancia que siguió a sus dirigentes aunque estuvieran presos.

El segundo discurso $(\mathrm{D} 2,1987)$ consiste en una estrategia de legitimación que apoya el ingreso del MLN-T en el Frente Amplio. Aquí se trata del dirigente que ha venido a desafiar el poder existente con una actitud crítica y que le propone a los grupos de izquierda desunidos una alianza mediante el ingreso del MLN-T al Frente Amplio con el objetivo último de tomar el poder.

El tercer discurso $(D 3,2009)$ exhibe una estrategia de apropiación para una acción conjunta de toda la izquierda uruguaya en las elecciones de 2009. Mujica se muestra como el motivador de una fuerza política dirigiéndose a un pueblo que es testigo de las obras realizadas por el Frente Amplio en el gobierno y por las cuales es criticado por la oposición.

El cuarto discurso $(D 4,2010)$ es una estrategia de institucionalización interna al asumir la presidencia del Uruguay. Mujica se presenta como instrumento y garantizador de la democracia frente a todo el país con su historia y sus virtudes cívicas que conforman el mito del Uruguay ${ }^{17}$, sus buenas maneras, su conciencia social por el otro, su énfasis por más latinoamericanismo.

El quinto discurso $(D 5,2011)$ se trata de una estrategia de institucionalización externa ante empresarios y otros actores internacionales. Mujica se construye como defensor del bienestar de un país chico y se dirige al país que sufre las asimetrías económicas frente a dos países grandes: Brasil, industria poderosa, elegida para advertirles cuáles van a ser las reglas de juego, y la Argentina, que construye como patria común (figs. 3 y 4 ).

Estos cinco discursos se sitúan en estas variantes estratégicas del campo discursivo utilizadas por Mujica durante su trayectoria política con el propósito de ampliar, por un lado, su influencia persuasiva nacional e internacional y, por el otro, polemizar con el adversario de turno. La lucha por el poder comienza en el seno de su propio grupo y se extiende hacia afuera con el transcurso del tiempo.

\subsection{Objetivos de la investigación}

Para iluminar sobre la coherencia discursiva en el discurso político del presidente Mujica y sobre su construcción del poder se estudiaron sus estrategias si-

\footnotetext{
17 Para un detallado análisis de los mitos fundamentales y fundacionales del imaginario social uruguayo véase Perelli \& Rial (1986, p. 15-37).
} 
guiendo la operativa tradicional para estudios de caso y lo que Catherine KerbratOrecchioni denomina el aparato de la enunciación dentro de la investigación cualitativa del análisis de discurso. El estudio tuvo por consiguiente dos etapas bien definidas: un análisis interno y otro interdiscursivo. En la primera etapa se analizó cada discurso individualmente bajo la lupa de la teoría de la enunciación en sentido restrictivo - consistente específicamente en la identificación de la subjetividad en el universo denominado Lenguaje de Mujica- en función de las reglas intuitivas que conforman el campo discursivo político. En la segunda etapa se compararon los discursos entre sí, tomados como una estructura común, cuya evolución diacrónica exhibió continuidades y rupturas.

Para descubrir y describir los mecanismos enunciativos del presidente, en el análisis de datos se elaboró un sistema propio clasificatorio ${ }^{18}$ a partir de la grilla de análisis de Kerbrat-Orecchioni, con los siguientes propósitos:

- proveer una evaluación de la naturaleza enunciativa de sus discursos, desde el más reciente al más antiguo, y desde una perspectiva de "inmanentismo abierto" (Kerbrat-Orecchioni, 1980, p. 283, y 1997, p. 220) ${ }^{19}$

- determinar los orígenes y las características de su narrativa, cómo la construye y quiénes son sus interlocutores

- explicar de qué manera la narrativa de sus discursos refleja o se inspira en la identidad uruguaya y su historia.

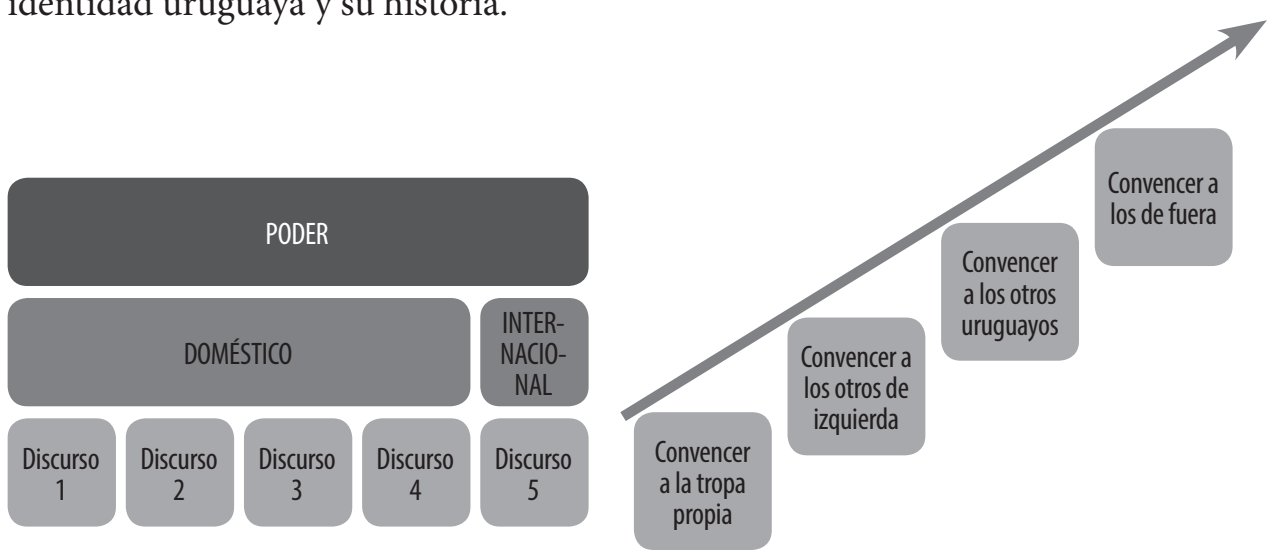

Figura 3. La construcción del poder.

Figura 4. La persuasión y la construcción del poder.

\footnotetext{
18 Está descripto en las tablas 1 y 2 .

19 El "inmanentismo abierto" consiste en admitir que es por el contrario legítimo, incluso necesario, acordar un lugar, en el seno de la lingüística, a ciertas consideraciones concernientes a las condiciones de producción/ recepción del mensaje".
} 
Aplicando al corpus el sistema clasificatorio y la grilla de Kerbrat-Orecchioni, se revisó el uso que el presidente hizo de los deícticos (huellas de la subjetividad del enunciador), los modalizadores (indicadores de la actitud del enunciador con respecto de su interlocutor y a sus propios enunciados) y un análisis de los enunciatemas y los subjetivemas (categorías lingüísticas de la subjetividad) (KerbratOrecchioni, 1980, p. 42). Para estudiar su trayectoria discursiva era indispensable realizar una cronología relevante de hechos históricos en Uruguay y una selección de hitos clave en su biografía política. Dada la escasez de narraciones o literatura revolucionaria que relatara de primera mano la intimidad histórica tupamara, hubo que consultar en segundas fuentes la historia de la época desde distintas perspectivas $^{20}$ - a riesgo de encontrar fechas y descripciones de eventos contradictoriospara acercarse lo mejor posible a la realidad y así poder situar a Mujica como el sujeto de enunciación, añadiendo al análisis una mejor comprensión de lo que dice en sus discursos y poder llegar a sus huellas de enunciación más tempranas.

\subsection{Las fases de la investigación}

\section{La matriz de análisis elaborada para la recolección de los datos}

Dado que Kerbrat-Orecchioni (1980, p. 202) advierte que "Toda secuencia lleva la marca de su enunciante, pero según modos y grados diversos”, para lograr discernir estas variaciones, la autora aplica el método restrictivo de análisis en una primera etapa y el método amplio o descriptivo en una segunda. Consecuentemente, la matriz de análisis desarrollada replicó sus dos etapas metodológicas, tanto para inventariar las unidades lingüísticas que remiten a la inscripción del sujeto dentro del enunciado, como para identificar los objetivos ilocutorios que modela el presidente Mujica al elegir mecanismos afectivos y argumentativos específicos para actuar sobre su(s) alocutario(s). Para ello se aplicaron sus categorías y clasificaciones de deícticos y subjetivemas, estructuradas en dos tablas para mayor claridad conceptual, las que se presentan a continuación. La primera etapa consistió en un análisis molecular concreto de la subjetividad que surge del sistema de referencia deíctico del sujeto-enunciador Mujica, y la segunda, en un análisis abstracto de la subjetividad que incorpora el carácter dialógico e intersubjetivo de todo discurso.

\footnotetext{
20 Sobre la historia política del MLN-T y cultura tupamara véase Aldrighi (2001) (2009), De Giorgi (2011), Fernández Huidobro (2012), Garcé (2009), Gatto (2000), Gilio (2011), Labrousse (2009) y Rey Tristán (2006).
} 


\subsubsection{Primera etapa: el método restrictivo de análisis}

De la aplicación al corpus de las dos tablas de categorías de deícticos y subjetivemas se obtuvieron datos iniciales que resaltaron la relevancia jerarquizada de estos índices de subjetividad lingüística. A partir de ella, se seleccionaron aquellos índices con mayor relevancia para el análisis argumentativo. A este respecto, guió la primera etapa el dictum de Kerbrat-Orecchini (1980, p. 257) al citar a Ducrot: "[...] hablar no es fundamentalmente informar, sino argumentar; no es decir cosas "nuevas", sino cosas que "traen consecuencias": un enunciado se justifica por su pertinencia argumentativa [...]".

La atención se focalizó en aquellos lugares lingüísticos de la enunciación donde Mujica se inscribía como sujeto-hablante. Se estudió su expresión subjetiva por excelencia y sus operaciones de objetivización o des-subjetivización, temática que surge de la visión que tiene Kerbrat-Orecchioni sobre la tensión que existe en el continuum del eje objeto-sujeto. El desglose de los textos para localizar las huellas de la enunciación de Mujica se realizó a partir del punto de vista de su fuente enunciativa para continuar con el análisis de las modalidades de inscripción de esa fuente en el enunciado. Este relevamiento de los enunciatemas del presidente fue fundamental para el análisis de sus presuposiciones (aquello que se supone conocido por el/los destinatarios) y las connotaciones asignadas a términos que utiliza. En resumen, las tablas contuvieron sintéticamente los índices de subjetividad deíctica y no deíctica, de subjetividad explícita e implícita, y cuatro categorías de los subjetivemas que reflejan los rasgos afectivo, evaluativo, modalizador y axiológico. Se trató de filtrar aquellas informaciones que mostraban rastros de la inscripción en el enunciado del sujeto de la enunciación.

\section{La categoría de los deícticos}

Kerbrat-Orecchioni (1980, p. 48) define a los deícticos como "las unidades lingüísticas cuyo funcionamiento semántico referencial implica tomar en consideración algunos de los elementos constitutivos de la situación de comunicación [...] lo que varía con la situación es el referente de una unidad deíctica, no su sentido, el cual permanece constante de un uso al otro [...]".

Las categorías y clasificaciones de deícticos propuestas por Kerbrat-Orecchioni están inventariadas en la tabla 1. 
Tabla 1. Clasificación de los deícticos según Kerbrat-Orecchioni.

\begin{tabular}{|c|c|c|c|}
\hline \multicolumn{2}{|c|}{ Categoría de enunciación } & \multicolumn{2}{|c|}{ Deíctico } \\
\hline \multirow{3}{*}{\multicolumn{2}{|c|}{ Pronombres personales }} & Yo (locutor), tú/vos (alocutario); & Deíctico puro \\
\hline & & Nosotros & Deíctico puro e inclusivo \\
\hline & & él/ellos/ellas (no alocutario) & Deícticos negativos y representantes \\
\hline \multirow{2}{*}{\multicolumn{2}{|c|}{ Pronombres demostrativos ${ }^{1}$}} & este, ese, aquel & $\begin{array}{l}\text { Deíctico por excelencia (eje de proximidad/ } \\
\text { alejamiento del denotado respecto del hablante) }\end{array}$ \\
\hline & & sintagma nominal acompañado por un gesto & Deixis por ostensión \\
\hline \multirow[t]{3}{*}{$\begin{array}{l}\text { Localización } \\
\text { temporal }\end{array}$} & Adverbios & $\begin{array}{l}\text { en este momento; ahora (simultaneidad); ayer; an- } \\
\text { teayer; el otro día; la semana pasada; hace un rato; } \\
\text { recién, recientemente (anterioridad); hoy; el lunes } \\
\text { (neutro); mañana; pasado mañana; el año próximo; } \\
\text { dentro de dos días; desde ahora; pronto; en seguida } \\
\text { (posterioridad) }\end{array}$ & Deícticos \\
\hline & Conjugación verbal & $\begin{array}{l}\text { Desinencias verbales; pasado, presente, futuro (to- } \\
\text { dos deícticos, salvo estilo indirecto) }\end{array}$ & Deícticos \\
\hline & Adjetivos temporales & Actual, moderno, antiguo, futuro, próximo & Algunos deícticos \\
\hline \multirow{4}{*}{$\begin{array}{l}\text { Localización } \\
\text { espacial }\end{array}$} & Adverbios de lugar & aquí/acá, ahí, allí/allá & Deíctico por excelencia \\
\hline & Frase preposicional & delante de/detrás de & Deíctico \\
\hline & Orientación lateral & a la derecha/izquierda & Deíctico \\
\hline & Verbos locativos & ir/venir; traer & Deícticos \\
\hline
\end{tabular}

1 Referenciales al contexto (representantes) o referenciales a la situación de comunicación (deícticos).

\section{La categoría de los subjetivemas}

Dentro del sistema de localización deíctica (yo-aquí-ahora), los hablantes tienden a organizar el espacio discursivo en torno de sus coordenadas espacio-temporales o bien seleccionando estructuras objetivas de un espacio en el que prefieren no proyectarse (Kerbrat-Orecchioni, 1980, p. 88). Sin embargo, los deícticos son solo un subconjunto de la totalidad de las unidades subjetivas que conforman a las unidades enunciativas. Se puede alargar la lista de categorías deícticas, añadiendo otras marcas de la subjetividad. La autora destaca especialmente las dos categorías léxicas en las que se inscribe la subjetividad: los axiológicos, portadores de un rasgo evaluativo del tipo bueno/malo (que afecta al objeto denotado por esa unidad y/o elemento cotextualmente asociado) y los modalizadores, portadores de un rasgo evaluativo de tipo verdadero/falso (y que a menudo presentan una connotación axiológica, ya que lo verdadero presupone unilateralmente lo bueno) (Kerbrat-Orecchioni, 1980, p. 156). Para los propósitos de esta investigación, 
existen además otras unidades subjetivas que contienen un valor emotivo y son de contenido evaluativo. Fueron todos esos lugares de anclaje subjetivo los que se intentó inventariar y clasificar en esta primera etapa de análisis de la lingüística de enunciación en su sentido más restrictivo, antes de aplicar una perspectiva ilocutoria global sobre los discursos del presidente. A su vez, se realizó el inventario y la clasificación de los subjetivemas en la tabla 2.

\subsubsection{Segunda etapa: el método descriptivo de análisis (semántico-pragmático)}

Un aspecto importante que fue clave para la elaboración del trabajo - y que Kerbrat-Orecchioni (1980) también resalta- es que una tipología de discursos solo se puede definir siempre y cuando se contemple su heterogeneidad y que "se admita la existencia superpuesta y jerarquizada de los distintos niveles de enunciación, que tiene status variables" (p. 216). La autora atribuye las siguientes propiedades a la dimensión discursiva: a) el discurso está deícticamente mar-

Tabla 2. Clasificación de los subjetivemas según Kerbrat-Orecchioni.

\begin{tabular}{|c|c|c|c|}
\hline \multirow{2}{*}{$\begin{array}{l}\text { Sustantivos } \\
\text { subjetivos }\end{array}$} & \multirow{2}{*}{ Axiológicos $^{1}$} & peyorativos (desvalorizadores) o elogiosos (valorizadores) & amor, acusación, belleza, pequeñez \\
\hline & & términos peyorativos sufijados & -acho/a; ete; -ucho/a; -astro \\
\hline \multirow{7}{*}{$\begin{array}{l}\text { Adjetivos } \\
\text { subjetivos }\end{array}$} & \multirow{3}{*}{ Afectivos $^{2}$} & inherente al adjetivo & ignorante, cobarde \\
\hline & & significante prosódico, tipográfico & ¡! \\
\hline & & significante sintáctico & anteponer adj. "pobre hombre" \\
\hline & $\begin{array}{l}\text { Evaluativos no } \\
\text { axiológicos }\end{array}$ & $\begin{array}{l}\text { evaluación cualitativa o cuantitativa del objeto, cuyo uso } \\
\text { se basa en una doble norma: interna del objeto al que se } \\
\text { atribuye la cualidad; específica del hablante. "Esta casa es } \\
\text { grande" según idea que tengo de grande. }\end{array}$ & $\begin{array}{l}\text { caliente, frío, caluroso } \\
\text { caro } \\
\text { largo/ancho; largo/corto } \\
\text { importante }\end{array}$ \\
\hline & \multirow{3}{*}{$\begin{array}{l}\text { Evaluativos } \\
\text { axiológicos }\end{array}$} & $\begin{array}{l}\text { - más marcados subjetivamente que otros adjetivos (índice } \\
\text { alto de subjetividad); } \\
\text { - doble norma en su empleo: 1) referida a la clase del objeto }\end{array}$ & $\begin{array}{l}\text { bello } \\
\text { útil }\end{array}$ \\
\hline & & $\begin{array}{l}\text { al que se atribuye; } 2 \text { 2) referida al sujeto de la enunciación y } \\
\text { relativa a sus sistemas de evaluación. } \\
\text { - aplican al objeto un juicio de valor positivo/negativo; } \\
\text { - los adjetivos no marcados pueden ser axiologizados. }\end{array}$ & Bueno/ malo (intrínsecamente axiológico) \\
\hline & & \multicolumn{2}{|c|}{$\begin{array}{l}\text { Nota: verbo introductorio o coordinador (cambia connotación): especifica valor axiológico, como "tratar de" } \\
\text { y"pero" (operador de inversión, ej. /valor/, pero /desvalor/); "hasta" coordina dos secuencias de mismo valor } \\
\text { axiológico. }\end{array}$} \\
\hline
\end{tabular}




\begin{tabular}{|c|c|c|c|c|}
\hline \multirow{13}{*}{ Verbos subjetivos } & $\begin{array}{l}\text { Axiológico: } \\
\text { bueno/malo; } \\
\text { Modalidad: } \\
\text { verdadero/ } \\
\text { falso/incierto }\end{array}$ & \multicolumn{3}{|c|}{$\begin{array}{l}\text { 1. ¿Quién hace el juicio evaluativo? locutor/actante (más importante para la perspectiva enunciativa) } \\
\text { 2. ¿Qué es lo que se evalúa? (proceso/objeto/hecho) } \\
\text { 3. ¿Cuál es la naturaleza del juicio evaluativo? }\end{array}$} \\
\hline & \multirow{7}{*}{$\begin{array}{l}\text { Ocasionalmente } \\
\text { subjetivos }\end{array}$} & \multirow{5}{*}{$\begin{array}{l}\text { evaluación } \\
\text { bueno/malo }\end{array}$} & \multirow{2}{*}{ Verbos de sentimiento } & gustar, apreciar, desear, querer, ansiar, amar \\
\hline & & & & odiar, detestar, subestimar, temer, lamentar \\
\hline & & & \multirow[b]{3}{*}{ Verbos de decir } & categoría 1 (nunca): caminar \\
\hline & & & & $\begin{array}{l}\text { categoría } 2 \text { (siempre): hablar, decir, } \\
\text { preguntar, criticar, balbucear }\end{array}$ \\
\hline & & & & $\begin{array}{l}\text { categoría } 3 \text { (algunos contextos): reafirmar, } \\
\text { repetir, agregar, continuar, terminar y lamentarse, } \\
\text { deplorar, quejarse de, pedir, alabar, censurar } \\
\text { elogiar, felicitar, criticar, acusar, condenar }\end{array}$ \\
\hline & & \multirow{2}{*}{$\begin{array}{l}\text { evaluación verdadero/ } \\
\text { falso/incierto }\end{array}$} & Verbos de percepción & ver \\
\hline & & & Verbos de opinión & $\begin{array}{l}\text { considerar, encontrar, pensar, estimar, juzgar, } \\
\text { tener la impresión, estar seguro, pensar, creer }\end{array}$ \\
\hline & \multirow{5}{*}{$\begin{array}{l}\text { Intrínsecamente } \\
\text { subjetivos }\end{array}$} & \multirow{2}{*}{$\begin{array}{l}\text { intrínsecamente } \\
\text { axiológicos (evaluación } \\
\text { bueno/malo) }\end{array}$} & $\begin{array}{l}\text { referencia al proceso } \\
\text { denotado y a uno } \\
\text { de sus actantes }\end{array}$ & $\begin{array}{l}\text { perpetrar/cometer (connotación mala); } \\
\text { reincidir (reiterar acto que se considera malo); } \\
\text { infligir; resentirse; fracasar, triunfar, } \\
\text { temer; revolcarse en (negativo); } \\
\text { dedicarse; degenerar/retroceder. }\end{array}$ \\
\hline & & & $\begin{array}{l}\text { afecta a uno y/u otro de } \\
\text { los actantes del proceso }\end{array}$ & $\begin{array}{l}\text { merecer (jerarquía de interpretaciones); } \\
\text { beneficiarse con, servirse de (bueno); } \\
\text { infligir (malo); privar de, soportar, } \\
\text { confesar, reconocer, admitir. }\end{array}$ \\
\hline & & \multirow{3}{*}{$\begin{array}{l}\text { intrínsecamente } \\
\text { modalizantes } \\
\text { (evaluación verdadero/ } \\
\text { falso/incierto) }\end{array}$} & Verbos de juzgar & axiológicos y modalizantes: acusar, criticar \\
\hline & & & Verbos de decir & $\begin{array}{l}\text { clase 1: decir, afirmar, declarar, sostener } \\
\text { clase } 2 \text { (modalizantes intrínsecos): } \\
\text { pretender (presuposición), reconocer, } \\
\text { confesar, admitir, pretextar. }\end{array}$ \\
\hline & & & Verbos de opinión & $\begin{array}{l}\text { imaginar, pensar, saber que; verbos } \\
\text { factivos positivos: lamentar, negar, saber, } \\
\text { confesar, sospechar; verbos factivos negativos: } \\
\text { mentir, aparentar, pretender, imaginarse; } \\
\text { modalizantes negativos: calumniar. }\end{array}$ \\
\hline \multirow{6}{*}{$\begin{array}{l}\text { Adverbios } \\
\text { subjetivos }\end{array}$} & \multicolumn{4}{|c|}{ Modalizadores: grado de adhesión (fuerte o mitigada) a los contenidos enunciados por sujeto enunciante } \\
\hline & \multicolumn{2}{|c|}{ Modalizadores (juicio de verdad) } & \multicolumn{2}{|c|}{$\begin{array}{l}\text { cierto, probable, dudoso, quizá, probablemente, sin duda, ciertamente, con } \\
\text { seguridad }\end{array}$} \\
\hline & \multicolumn{2}{|c|}{ Modalizadores (juicio sobre realidad) } & \multicolumn{2}{|c|}{ realmente, verdaderamente, efectivamente, de hecho } \\
\hline & \multicolumn{2}{|l|}{ Adverbios } & \multicolumn{2}{|c|}{ francamente, personalmente, sinceramente, obviamente; ya, todavía, aun. } \\
\hline & \multicolumn{2}{|c|}{ Expresiones restrictivas y apreciativas } & \multicolumn{2}{|c|}{ apenas, casi, no ... mas que, solo } \\
\hline & \multicolumn{4}{|c|}{ Conectores preposicionales: } \\
\hline
\end{tabular}

1 Término axiológico: positivo, negativo o neutro.

2 Enuncian una reacción emocional del sujeto hablante frente a un objeto (Kerbrat-Orecchioni, 1980, p. 111). 
cado; b) el discurso está sometido a reglas heterogéneas que dependen del contexto enunciativo; c) todo discurso y/o interdiscurso es siempre interpelativo o apelativo en relación con otros discursos; d) la relación entre discursos implica interpretaciones y traducciones; y e) las instancias de la enunciación puestas en discurso tienen su fuente en la subjetividad enunciante: el discurso es constitutivo de su contextualización. La heterogeneidad se refiere a los diversos grados de valor que puede tomar la subjetividad dentro del enunciado y la infinidad de capas de significado posibles entre los polos del continuo objeto-sujeto.

La autora también destaca la ambigüedad que tiene la noción de subjetividad, lo cual implica estudiar no solo los deícticos, que dependen de determinados datos de la situación de comunicación, pero también otras categorías lingüísticas de la subjetividad cuya manifestación están determinadas por la competencia cultural y la competencia ideológica de su usuario (Kerbrat-Orecchioni, 1980, p. 193). Es decir, determinadas informaciones sobre el enunciador son críticas para evaluar la incidencia de subjetividad manifiesta en su enunciado. KerbratOrecchioni (1980) escribe a este respecto: "Los marcadores de subjetividad pueden más o menos confesar o, por el contrario, disimular, su condición de unidades subjetivas" (p. 195). Argumenta que si bien existen procedimientos lingüísticos para producir un efecto de objetividad, por definición casi todo enunciado es subjetivo y también agrega que "muy pocas palabras se escapan del naufragio de la objetividad" (Kerbrat-Orecchioni, 1980, p. 189). Esta polaridad continua entre subjetividad y objetividad resulta en la ambigüedad del "concepto de subjetividad", lo que la lleva a analizar dos facetas importantes: la inscripción del locutor en su enunciado y la inscripción de su(s) alocutario(s) en este mismo enunciado. La subjetividad en el sentido restrictivo estudia la enunciación desde la perspectiva del sistema de referencia deíctica del sujeto enunciador en el momento presente de la situación de comunicación, y en el sentido descriptivo incorpora a los otros actantes y a distintas variables del modelo de comunicación revisado de Kerbrat-Orecchioni mediante el cual el locutor construye una imagen de sus alocutarios y define su posición frente a cada uno de ellos. En este análisis más descriptivo se estudian las representaciones simbólicas o la imagen de y la distancia o aproximación como proceso interactivo y dialógico. 


\subsection{Organización y relevamiento de los datos}

Durante el relevamiento se realizaron diferentes niveles de lectura de los discursos, comenzando por la identificación de deícticos en una primera etapa y terminando por la identificación de enunciados paradigmáticos. Durante el ejercicio, la lectura analítica incluyó también otros niveles, tales como los relativos a la subjetividad en el lenguaje de Mujica, sus recursos discursivos a la luz de la literatura sobre el análisis del discurso político y sus tácticas, tal como son descriptas por la teoría de la comunicación respecto de la construcción de la legitimización, la búsqueda de consenso, lo imaginario y lo simbólico en la construcción de la identidad, etc.

\section{La interpretación de los datos y primeros hallazgos}

El campo discursivo es el lugar de intersección de varios enunciados, donde el enunciador construye su enunciado en estricta relación con otros enunciados (en adhesión u oposición) para así reforzar sus propias creencias, distinguiéndolas de los postulados de estos otros enunciados o disminuyendo su peso relativo. La construcción del relato se da a partir de las estrategias que asume el enunciador.

El propósito inicial de la investigación era identificar las estrategias enunciativas que utilizó y utiliza Mujica para la construcción de un relato con identidad propia. Interesaba descubrir cómo se generaba ese relato, a qué fuentes de legitimidad acudió para nutrirlo (los valores y experiencias de su vida), cómo progresó, se modificó o se adaptó en el tiempo, y cómo mantuvo su coherencia interna. Por otro lado, si la función última del discurso político es persuadir o convencer, Mujica logró una comunicación eficaz que le consiguió adhesiones.

La oratoria tradicional del país es una habilidad que también posee Mujica y que desarrolló aun más durante su militancia como miembro del MLN-T cuando la describe como nuestra cultura no escrita ${ }^{21}$. La naturaleza misma del grupo clandestino obligó a sus miembros y simpatizantes a desarrollar esta capacidad oral para comunicarse y organizarse. La participación de Mujica dentro de esa agrupación le otorgó el uso de un léxico propio revolucionario cuyos ideologemas (Kristeva, 2001, p. 148) contribuyeron a la construcción de su discurso y de un colectivo de identificación en el cual se reconoce el enunciador discursivo. Entre esos

\footnotetext{
21 Enunciado tomado del discurso pronunciado en el Platense Patín Club el 17 de marzo de 1985, 48 horas después de la liberación de Mujica de la cárcel. Discurso 1, línea 91.
} 
ideologemas de sus discursos se encuentran términos y expresiones verbales que remiten a un léxico de formación ideológica bien definida (lucha, filas, guerra contra el enemigo, vencer) o a los simbolismos uruguayos del doctrinario nacionalista y popular ("patria para todos", "patria grande", pueblo, Artigas, orientales todos, etc.). Este conjunto semiótico constituye un eje importante del paradigma discursivo del presidente, que además adorna con otros recursos expresivos tomados de los idiolectos de la calle y el campo, de expresiones panteístas de la naturaleza o de la docencia política, y que va adaptando a las realidades de sus audiencias a lo largo del tiempo, es decir que adapta a cada situación o necesidad puntual de comunicación, pero sin dejar de variar en su identidad.

Mediante el análisis discursivo diacrónico, se identificó la evolución de las palabras-lengua-discurso de Mujica y se observó una continuidad en los temas filosóficos que constituyen sus grandes enunciados paradigmáticos: pilares centrales ellos que sirven además de apoyo y marco a otras tantas ideas diversas y contradictorias, habida cuenta que las cosmovisiones son complejas y resistentes al cambio y pueden, por lo tanto, integrar elementos divergentes y aún contradictorios (que a veces terminan juntándose en "un gran guiso", como los calificó el propio presidente). Partiendo de una plataforma filosófica que podría calificarse de panteísta y mediante su oralidad y desde el núcleo invariante de sus valores, Mujica logra plantar una cosmovisión, un marco o paradigma para interpretar el mundo en la mente de sus oyentes, sean estos sus compañeros de la militancia de antaño, sus camaradas de la izquierda uruguaya, todos los ciudadanos uruguayos o los grupos económicos internacionales con intereses presentes y futuros en el país.

Otro hallazgo preliminar que arrojó el tratamiento de los datos es una clara evolución retórica del presidente. En primer lugar, si de joven fue blanco conservador, su lenguaje de hombre de acción toma como propios reclamos sociales que se radicalizan progresivamente. Ya maduro, modera tal lenguaje para adaptarlo al tono que los uruguayos normalmente prefieren escuchar aunque sean ideas radicales, moderación que mantuvo a lo largo de su campaña presidencial mediante un discurso construido sobre las prioridades sentidas por la ciudadanía. Según Riorda (2006, p. 5), este "construccionismo" ${ }^{2}$ sostiene que "la fundamental premisa que esta perspectiva invoca es que la realidad es un producto social, y que los primeros significados por los cuales la realidad es construida, pertenecen al lenguaje”.

22 Consultado el 26 de septiembre 2014 en: http://www.cienciared.com.ar/ra/usr/9/257/fisec04riorda.pdf 
En segundo lugar, Mujica utilizó lenguajes simbólicos que sirvieron para crear lazos de confianza y su retórica funcionó como instrumento de interacción social creando dinamismo entre emisor y oyente. Exhibió, cuando fue necesario, cambios de registro y estilo en sus exposiciones públicas: a) registro alto de militante de izquierda; b) lenguaje del hombre de campo, especialmente con imágenes inspiradas en la naturaleza; y, c) registro lingüístico informal o no elaborado de los sectores sociales más pobres. Este estilo de comunicación directa le permitió construir puentes con los tres sectores de la sociedad que le eran más importantes: el establishment, los medios de comunicación y la opinión pública, mediante el uso de diferentes registros y léxicos lingüísticos propios de cada audiencia.

En su búsqueda de consenso con estos sectores, cuyos intereses particulares demostró entender, construyó modelos de comunicación distintos para cada audiencia y se ajustó a ese entendimiento. Al establishment le demostró su comprensión sobre el poder social y los negocios y le dio su lugar en la sociedad uruguaya. Abrió a la prensa y la radio un acceso directo a su persona política y privada, concediendo entrevistas informales y espontáneas que le trajeron la simpatía de los medios de comunicación. De ahí la decisiva exposición mediática de su personalidad empática con temas populares que los medios dieron a conocer a la opinión pública. Su capacidad de utilizar un lenguaje sencillo y su dominio de un registro sofisticado le sirvieron en la elaboración de una comunicación política propia, que es "la metonimia de un proyecto mayor y cuya expresión ayuda a su legitimación" (Elizalde, Fernández Pedemonte \& Riorda, 2006, p. 82). Ante las dudas sobre su pasado guerrillero y su peculiar estilo logró obtener credibilidad frente al resto del mundo mediante un discurso pacificador dirigido al universo completo, a sus compatriotas y a sus contrincantes: "Lo mejor es tener mucha oreja. Hay que escuchar en primer término a aquellos que no concuerdan con nosotros, porque sus razones tienen y son parte de una realidad".

En tercer lugar, como líder político, Mujica construyó una narrativa basada en ideas macroeconómicas de origen conservador sobre las cuales montó un ideario social de izquierda para construir un futuro para su país, visión a la que ha hecho alusión en varios de sus discursos, pragmatismo ideológico que, al alejarlo del enfrentamiento del bipartidismo tradicional ${ }^{23}$, le ha ayudado a apropiarse de ideales y valores

23 En las propias palabras de Mujica: "En la interpretación histórica de este país soy blanco. Blanco, y separemos al Partido Nacional que es otra cosa” (García, 2009, p. 17). 
para su narrativa que son preexistentes y compartidos por la mayoría de la sociedad uruguaya. A este respecto, valen los comentarios del dirigente colorado opositor Julio María Sanguinetti, en una entrevista en el Foro Militar General ${ }^{24}$ en la semana de la asunción de Mujica, subrayando el fuerte contenido simbólico que implicaba su triunfo 25 años después del retorno a la democracia y de haber estado preso.

Se descubrió en los dos primeros discursos del corpus que Mujica introduce una proto-teoría (Zanotti, 2005, p. 106) que busca la introducción de un cambio al estático modelo político bipartidario uruguayo. En el pensamiento de Thomas Kuhn, esta prototeoría o paradigma partiría del horizonte de precomprensión o intuiciones que tiene Mujica que consisten en la búsqueda de una nueva interpretación de la organización política que debería tener el país, rompiendo con el anterior paradigma que dejaba fuera de la sociedad a grandes segmentos de la población. La prototeoría que desarrolla Mujica en su primer discurso y que constituye, en la terminología propuesta por Verón, un "núcleo invariante" de valores se basa en la conjugación de un campo discursivo propio y la adaptación de estrategias en diacronía. Esa prototeoría la resume el propio presidente en dos párrafos del primer discurso:

Nuestros dos viejos partidos tradicionales no son ni por asomo algo que merezca desprecio, porque si los despreciamos desconocemos la esencia de este país. Y es bueno que los hombres de izquierda empiecen a poner las patas en el suelo, a repensar la historia nacional y después refabricar nuestros propios esquemas.

Los tupamaros tenemos diferencias, aun entre los hombres de la guardia vieja. Perdonen, compañeros, yo no tengo empacho en decir, ni me piden que lo diga, que en mi interpretación histórica de este país soy blanco, perfectamente blanco. No por blanco menos tupamaro, y como pertenecemos a una organización que no robotiza el cerebro de los hombres, tengo la libertad suficiente para decir nuestro modo de pensar personal, que interpreta el de muchos otros compañeros, pero no necesariamente el de todos. Y sin embargo seguimos siendo el mismo equipo. Que para nosotros que no tememos golpear contra las vacas sagradas de la historia, así categóricamente decimos que somos blancos, y mídase que decimos blancos, no Partido Nacional ${ }^{25}$.

El núcleo invariante se basa en esta afirmación de principios que se encuentra repetidamente en el campo discursivo de Mujica. Si bien podría suponerse que esta ruptura paradigmática surgió de una crítica al paradigma político dominante por parte de un grupo de personas (entre ellas el propio Mujica, quien lo acusa de

\footnotetext{
24 http://www.militar.org.ua/foro/gobierno-del-presidente-jose-mujica-t25378.html

25 Enunciado tomado del discurso pronunciado en el Platense Patín Club el 17 de marzo de 1985, 48 horas después de la liberación de Mujica de la cárcel. Discurso 1, líneas 155-167. La negrita es nuestra.
} 
"falsedad"), en este caso se centra en la interpretación que Mujica como sujeto hace de la verdad mediante su objeto-discurso (campo discursivo). Cabe recordar que el núcleo invariante permanece estable a lo largo de toda la extensión del campo discursivo, es decir que comprende todo el universo de discursos. La construcción de su propia legitimación nace de esta dinámica intradiscursiva y se construye con "el interés del enunciador como transfigurado por el interés colectivo" (Verón, 1987, p. 24). El enunciador debe demostrar la verosimilitud de su relato mediante la exposición de enunciados contrarios o disimiles al suyo propio; la relación intersubjetiva entre los protagonistas del intercambio comunicativo, es decir, el "yo" en relación con los "otros".

La construcción del relato de Mujica se da mediante las distintas negociaciones que realiza como enunciador discursivo con sus adherentes, contrincantes y otros destinatarios (explícitos, encubiertos o indirectos), creando una imagen de sí mismo en relación con las voces que pone en escena en su campo discursivo. Verón (1987) identifica esto como un rasgo propio del discurso político, el "desdoblamiento en la destinación", lo que presupone una construcción dirigida a múltiples destinatarios que define como: 1. el prodestinatario o destinatario positivo que es el partidario; 2. el contradestinatario o destinatario negativo que es el adversario; y 3. el paradestinatario o el tercer hombre que está fuera del juego y es un espectador.

A su vez, García Negroni y Zoppi Fontana (1992) destacan que la multifuncionalidad del discurso político, con sus facetas de función de refuerzo, función de persuasión y función polémica, constituye uno de los elementos fundamentales que determinan su especificidad dentro del campo del discurso social. Verón (1987, p. 16) explica cómo el acto de enunciación política construye la imagen del enunciador: "La cuestión del adversario significa que todo acto de enunciación política supone necesariamente que existen otros actos de enunciación, reales o posibles, opuestos al propio". El acto de enunciación es a la vez réplica y anticipo de una réplica. Además, el discurso político construye simultáneamente tres destinatarios y, por ende, sus funciones son de refuerzo, de polémica y de persuasión para conseguir una respuesta por parte de sus prodestinatarios, contradestinatarios y paradestinatarios, respectivamente. "Es evidente que el campo discursivo de lo político implica enfrentamiento, relación con un enemigo, lucha entre enunciadores. Se ha hablado, en este sentido, de la dimensión polémica del discurso político. La enunciación política parece inseparable de la construcción del adversario" (Verón, 1987, p. 16). 
Por consiguiente, el campo discursivo de lo político depende del papel protagónico del sujeto en relación con otros potenciales enunciadores, y por ello la teoría de la enunciación es claramente central para la evaluación de la dinámica de la intersubjetividad que se construye a través de la identidad y el relato del sujeto enunciante, quien diseña sus enunciados en respuesta a otros enunciados en los procesos de producción y recepción de sentido. Interesa particularmente hacer hincapié en esta dimensión polémica del discurso político por cuanto es mediante este ejercicio dialéctico con un adversario como el enunciador otorga legitimidad a sus creencias y posturas en un intento de disminuir el poder de las palabras del otro e incrementar la validez o verosimilitud de las propias palabras. En este sentido, el enunciador construye su relato dirigiéndose a un alocutario positivo del mismo modo que contempla a su alocutario negativo, mientras logra también dirigirse - quizás indirectamente- a los alocutarios que están fuera del juego de este intercambio intersubjetivo con el propósito de conseguir mayores adherentes a sus creencias y posturas.

En el corpus se ha identificado que el adversario de Mujica puede aparecer corporizado tanto como una estructura conceptual como una persona con nombre y apellido. Así, por ejemplo, en D1 el adversario elegido son las estructuras mentales de la militancia (la conciencia de la juventud tupamara), por ejemplo: "Lo que vale es la causa, no el apellido" (D1, 1987, 1.86); en D4 son las estructuras sociales injustas de la sociedad uruguaya, por ejemplo: "manifestaciones de una sociedad que se va volviendo cínica" (D4, 2010, 1.290); y en D5 son las estructuras de dominación económica, tanto nacionales como internacionales, por ejemplo: "esa competencia es asimétrica, es en contra nuestro" (D5, 2011,1.74). A su vez, en D2 y D3, el enunciador Mujica se enfrenta con diferentes adversarios de ideales políticos opuestos (los blancos, Wilson Ferreira Aldunate, la derecha, etc.), por ejemplo, "el señor Wilson se permite el lujo" (D2, 1987, 1.50), "respuestas de un señor omnipotente como la de Wilson (D2, 1987, 1.57), "el malón fascista" (D2, 1987, 1. 231), "las oligarquías criollas entreguistas" (D2, 1987, 1.207), "una democracia mentirosa [...] como escondiendo aquí y allá en el 'veremos' de un señor ministro, la amenaza del garrote" (D2, 1987, 1.8). Por otro lado, el uso que hace de la alteridad se observa en la utilización que realiza de otros recursos, tales como la nominalización al referirse a la necesidad de "la participación" (dirigido a un destinatario positivo) y cuando critica "el diletantismo" (dirigido a un destinatario negativo). 
Luego de haber identificado la presencia de un adversario en cada uno de los discursos de Mujica, se confirma la idea de que "el discurso político no parece poder constituirse sin adversarios" de García Negroni y Zoppi Fontana. A su vez, también habría sustentación para la validez de otra noción de ZoppiFontana sobre el "discurso referido" cuando Mujica busca hablar por o reproducir la voz del pobre "éramos pobres [...] hoy hablo por los pobres [...] los entiendo [...] soy pobre". En el nivel de funcionamiento de los componentes se encuentran las modalidades mediante las cuales Mujica construye relaciones con las entidades del imaginario político y que están comprendidos dentro de cuatro zonas de sus discursos: 1) la del componente descriptivo (constatación/saber colectivo; el enunciador es fuente privilegiada de descripción y de las modalizaciones apreciativas); 2) la del componente didáctico (enuncia un principio general, una verdad universal; marcas de subjetividad menos frecuentes); 3) la del componente prescriptivo (deber/deontológico; imperativo universal; puede estar marcado subjetivamente o distanciamiento; campaña electoral); y 4) la del componente programático (promete, anuncia, se compromete a/poder hacer; infinitivo o nominalizaciones).

\subsection{Identificación de la subjetividad y su incidencia}

A diferencia de la lingüística, la teoría de la enunciación introdujo el interés por el hecho pragmático de la comunicación entre las personas. Esta teoría se centra en el momento siempre nuevo y repetido en que un sujeto toma el lenguaje para utilizarlo produciéndose en discurso. Se trata del lenguaje de alguien para alguien en un contexto concreto, con una determinada intencionalidad y contextos no lingüísticos que producen sentido.

Al haber ya realizado un análisis interno aplicando a cada discurso la lupa del modelo restrictivo de Kerbrat-Orecchioni, que estudia las huellas de inscripción del sujeto - por cuanto toda enunciación es egocéntrica a partir del "yo" en el "aquî" y en el "ahora" - se siguió con la comparación entre discursos bajo una interpretación descriptiva propia. En lo que a la teoría de la enunciación se refiere, se concluye que no se trata solo de subrayar la frecuencia del uso del "yo-aquí-ahora" sino que, lo que aparentemente sería natural al discurso político, la evocación de un "nosotros inclusivo", también es indicador de la presencia subjetiva. Como puede observarse en las tablas de clasificación de deícticos, Kerbrat-Orecchioni incluye el pronombre personal "nosotros" y lo designa "deíctico puro e inclusivo". 
Los deícticos relevados con las tablas clasificatorias fueron contabilizados numéricamente y, mediante el programa Excel, visualizados para su análisis en las figuras $5,6,7$ y 8 .

Frente a los hallazgos que generaron los datos, se intentó contestar como ejercicio previo la pregunta ¿cuál de los cinco es el discurso más subjetivo? y se descubrió la complejidad de las tareas que involucraba el análisis.

La primera intuición llevó a responder que fue el segundo discurso (D2, 1987), mediante el cual Mujica solicitó el ingreso de su fuerza MLN-T al Frente Amplio, partido mayoritario de la izquierda, discurso fuertemente cargado de subjetividad por el alto contenido de disputa que existía con un opositor que le servía para construirse a sí mismo, a sus ideales, y para crear una imagen peyorativa de este adversario. Es en este discurso que Mujica presenta una tesis política y, contradictoriamente, es el mismo discurso en que no aparece una huella directa del sujeto enunciante mediante el "yo". El adversario es designado desfavorablemente de manera creativa y variada, y enfrenta lo que Mujica denomina "el gran embate" de la "oligarquía" contra el "pueblo" mediante la elaboración de una dialéctica clara entre un "nosotros" unido frente a un "él" despreciable. Llama la atención la preponderancia del deíctico "nosotros" y la ausencia casi total del "yo" (casi, porque para que alguien emita un discurso no puede escapar a la subjetividad por completo, $y$ esto se percibe en la alta incidencia de subjetivemas

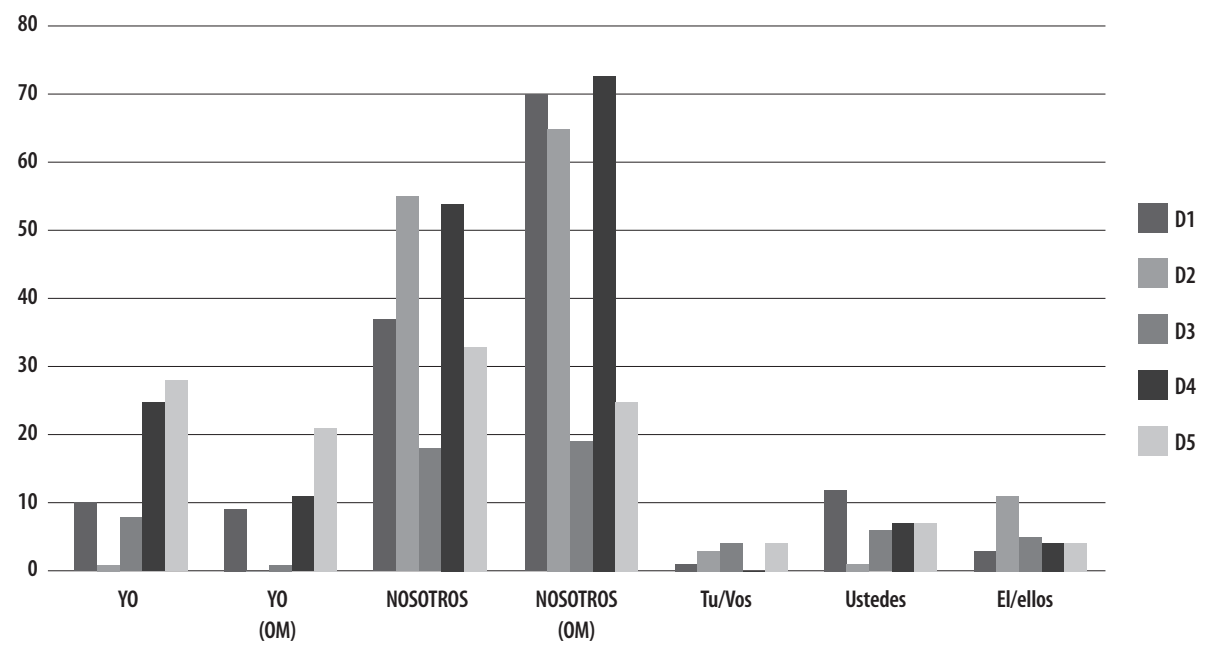

Figura 5. Frecuencias de pronombres personales deícticos en los cinco discursos. 
para descalificar al "otro"). Cabe destacar el único uso de la primera persona del singular donde se lee: "una sociedad donde lo mío y lo tuyo no la dividan en clases antagónicas, por un tipo de sociedad donde solo sean privilegiados los niños, los ancianos y los débiles, por un tipo de sociedad donde el hombre pueda ser verdaderamente solidario" (D2, 1987, 1.267). El significado de este pronombre personal tiene un sentido universal que está directamente relacionado con la concepción de solidaridad que tiene Mujica (valor central de la filosofía del Hombre Nuevo). Con respecto de los demás discursos, cobra mayor intensidad la presencia de "él" y, aunque Kerbrat-Orecchioni lo clasifica como "deíctico negativo", interpretamos que le sirve a Mujica para construirse a sí mismo frente a un adversario y, por consiguiente, el enunciado contendría un alto nivel de subjetividad.

Al continuar con este intento de definir cuál es el discurso más subjetivo, llaman la atención los dos últimos discursos del corpus (D4 y D5) pronunciados por Mujica luego de haber accedido a la presidencia; esto es, si se toma como deíctico central al "yo" o, bajo la nomenclatura de Kerbrat-Orecchioni, al "deíctico puro". El D4 exhibe una cantidad de 36 "yo" y una preponderancia del "nosotros", mientras que el D5 contiene una cantidad casi equivalente de "yo" y "nosotros" y cuatro "tu", los que constituyen deícticos puros en la clasificación de Kerbrat-Orecchioni.

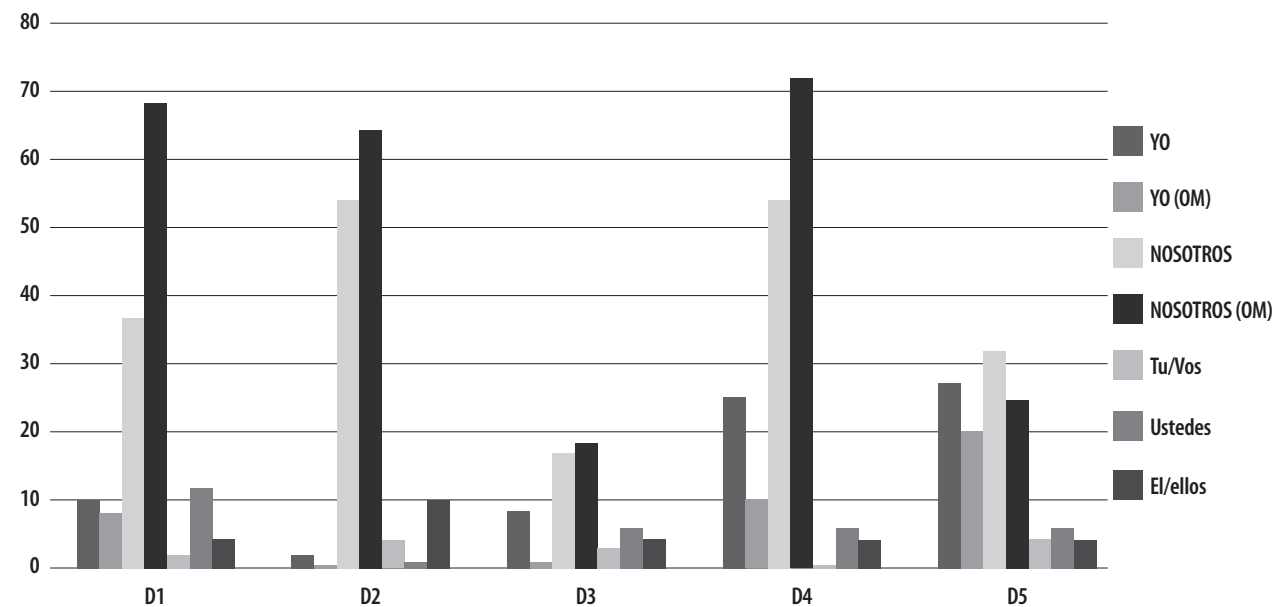

Figura 6. Frecuencias de pronombres personales deícticos en cada discurso. 
Si nos enfocamos en los pronombres personales deícticos, observamos una clara evolución de un "nosotros-ustedes" (D1), seguido de un "nosotros-él" (D2), hacia finalmente un "nosotros-yo" que caracteriza a los últimos tres discursos, llegando a una frecuencia casi equivalente de "nosotros" y "yo" en el último discurso. Tal como se observa en la figura 5, existe una alta y casi equivalente frecuencia del "nosotros" en los primeros dos discursos, así como en el cuarto. En este mismo gráfico cabe también señalar la aparición de un "yo" en los dos últimos y más recientes discursos que se manifiesta en forma de "mi/me" (yo implícito) en el D4, discurso de asunción presidencial, y en forma del "yo explícito" en el D5, discurso dado a la comunidad empresaria.

En líneas generales, se propone que los discursos D2 y D5 son altamente subjetivos puesto que el estilo argumentativo del orador se basa en concesiones o en la negociación de diferencias. Este último discurso difiere de los anteriores en que exhibe un equilibrio en el uso del "yo-nosotros" y no tiende hacia el uso exclusivo de un solo pronombre deíctico como se ha visto con la preponderancia del "nosotros" en D1, D2, D3 y D4, seguido por un pronombre secundario dominante, como por ejemplo se ve en D1 con "ustedes", en D2 con "nosotros", y en D3/D4/D5 con "yo". No obstante, se observa una continuidad en el uso mayoritario del "nosotros".

En definitiva, la pregunta sobre cuál es el discurso más subjetivo no es posible de ser contestada por cuanto Mujica opta por diferentes estrategias de uso de la subjetividad, lo que hace que un discurso no sea menos o más subjetivo que otro. Es conjetura que la profunda ideología socialista que inspira sus valores hace que su idea de sí mismo pertenezca a lo colectivo, a una identidad común de la nación uruguaya, y ello muestra una clara evolución (o progresión) del ethos-pueblo hacia un ethos-nación que se visualizará más adelante en la figura 9.

No es muy frecuente la referencia que realiza Mujica a sí mismo como individualidad en sus discursos si la comparamos con la presencia de otras personas o alocutarios, pero es llamativo el incremento que experimenta la presencia del "yo" en los últimos dos discursos. ¿A qué se debe este aumento? Podría atribuirse cierto peso al hecho de que las dos últimas conferencias fueron pronunciadas luego de asumir el poder presidencial y el enunciador debía emitir mensajes de legitimización con el fin de mantenerlo. En contraste, los discursos pronunciados al inicio de su carrera política hacen uso de subjetivemas para calificar o descalificar a las personas en su relato y no recurre a deícticos de primera persona. 
Como muestran los datos de la figura 7, los tres primeros discursos reflejan una baja frecuencia del uso del deíctico "yo". Además, esos discursos cobran mayor fuerza subjetiva por el uso que realiza Mujica de subjetivemas y otros deícticos de persona, locación y tiempo diferentes al “yo". Mujica se borra estratégicamente a sí mismo favoreciendo el uso del deíctico "nosotros" y fundiéndose con el ethos-pueblo mediante un "nosotros inclusivo" y empleando la función emotiva en su narrativa. Por el contrario, al introducirse a sí mismo en los últimos dos discursos con mayor frecuencia no significa que tengan una mayor carga subjetiva al utilizar el primer pronombre personal del singular "yo", "mi", "me", sino que se hace cargo de su alta responsabilidad como mandatario y manifiesta su compromiso institucional con ese papel. Se interpreta que el actor principal en el D4 es la sociedad uruguaya y el país en su conjunto en el D5.

Una última observación tiene que ver con la validez metodológica de comparar discursos improvisados contra otros formalmente preparados y escritos para deducir cómo Mujica construye su relato, tal como es el caso ejemplificado del D3, que es la transcripción de un video de una charla espontánea con lugareños de Cerro Largo en plena campaña política, versus el D4 de asunción del mando presidencial. Así se observa que el D2 y el D4 son más formales, ya que fueron redactados previamente y se pronunciaron en momentos históricos clave.

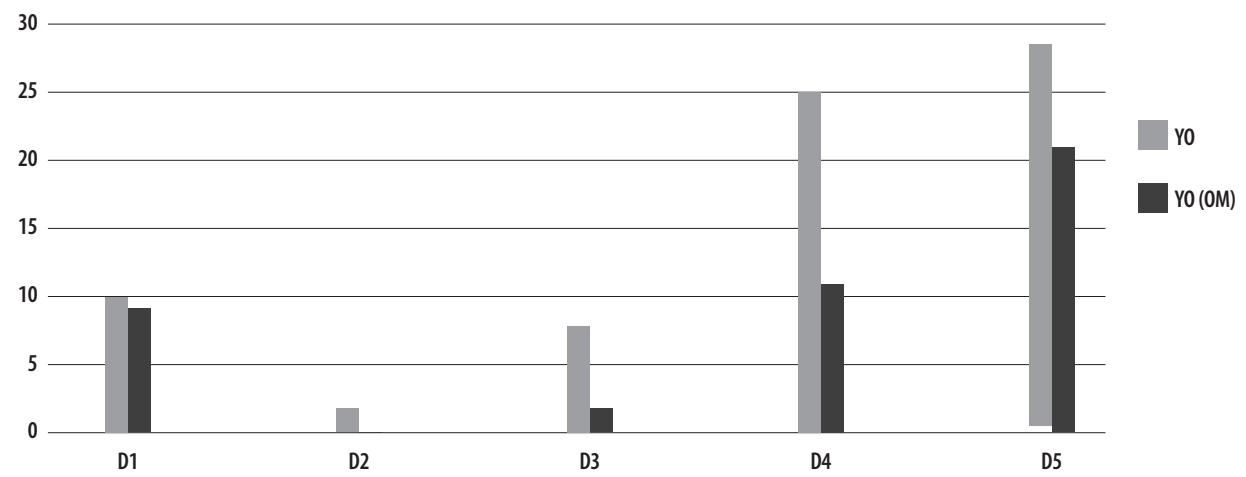

Figura 7. Frecuencias del Yo enunciador (deíctico de primera persona). 
Si se complementan los datos recogidos en las tablas de frecuencia de deícticos, la contabilización realizada en la tabla 3 estaría indicando que el mayor número de deícticos puros - consistente en las huellas de la situación de comunicación en sus dos ejes principales, es decir, en las coordenadas del espacio y el tiempo presentes (aquí-ahora), sin tomar en cuenta el sujeto (yo) - se encuentran en D2 y D4.

Si bien ya se comprobó en la figura 7 que el "yo" recién aparece en los últimos dos discursos, y que el "nosotros inclusivo" y una alta densidad de subjetivemas es característico del D2, esta tabla también muestra que los deícticos locativos y temporales tienen mayores incidencias en D2 y D4, lo que confirma en ellos altos niveles de subjetividad. Además, es pertinente mencionar que el D2 y D4 se pronunciaron en hitos de gran significancia histórica puesto que se trata, por una parte, del ingreso a la legitimidad política de los tupamaros mediante su incorporación al Frente Amplio y, por otro lado, de la asunción presidencial de un antiguo revolucionario quien busca probarle al país su compromiso de cumplir con las normas republicanas de la democracia y mantener el poder que ha legítimamente ganado mediante el voto electoral.

Cada enunciador elige diferentes estrategias y combinaciones de uso de un adversario, de la presencia del "yo" en forma subjetiva u objetiva, según el caso. En Mujica, el "yo-aquí-ahora" se da con mayor frecuencia en D2 y D4 y se debe al hecho de que estos corresponden a dos hitos importantes en la carrera política del orador. Se puede preguntar: ¿el uso de la subjetividad tendrá algo que ver con algo importante en juego? ¿El poder, por ejemplo? La búsqueda de una respuesta a esta pregunta está más allá del límite de esta investigación.

Por último, la figura 8 ilustra la intensidad de la subjetividad según el modelo propuesto por Kerbrat-Orecchioni y muestra que, por la fuerte concentración de deícticos, los discursos más subjetivos serían D4 y D5.

Tabla 3.

\begin{tabular}{lccccc}
\hline & D1 & D2 & D3 & D4 & D5 \\
\hline Hoy & 2 & 17 & 1 & 13 & 9 \\
\hline Ahora & 0 & 1 & 0 & 8 & 0 \\
\hline Aquí/acá & 4 & 8 & 1 & 8 & 5 \\
\hline TOTAL & 6 & 26 & 2 & 29 & 14 \\
\hline
\end{tabular}




\subsection{Análisis cuantitativo de los deícticos}

Los resultados de la contabilización en la tabla 4 de los totales de cada deíctico personal de primera, segunda y tercera persona en los distintos discursos contienen algunas variaciones que resultan pertinentes resaltar por cuanto estarían indicando estrategias específicas de subjetividad elegidas por Mujica. En particular, llaman la atención las siguientes: 1) un destacado aumento de la utilización de la primera persona del singular por parte del enunciador en los dos últimos discursos (con una fuerte presencia del imperativo); 2) una tendencia por la utilización de la primera persona del plural o "nosotros inclusivo" por parte del enunciador en la mayoría de los discursos y más enfáticamente en los primeros dos discursos cuya naturaleza resalta fuertes rasgos ideológicos; 3) la presencia de un fuerte adversario en D2, con la mayor evocación de la tercera persona del singular por parte del enunciador; y, 4) una pronunciada y evidente evocación a la segunda persona del plural "ustedes" en el primer discurso que se dirige a la juventud tupamara y sus simpatizantes.

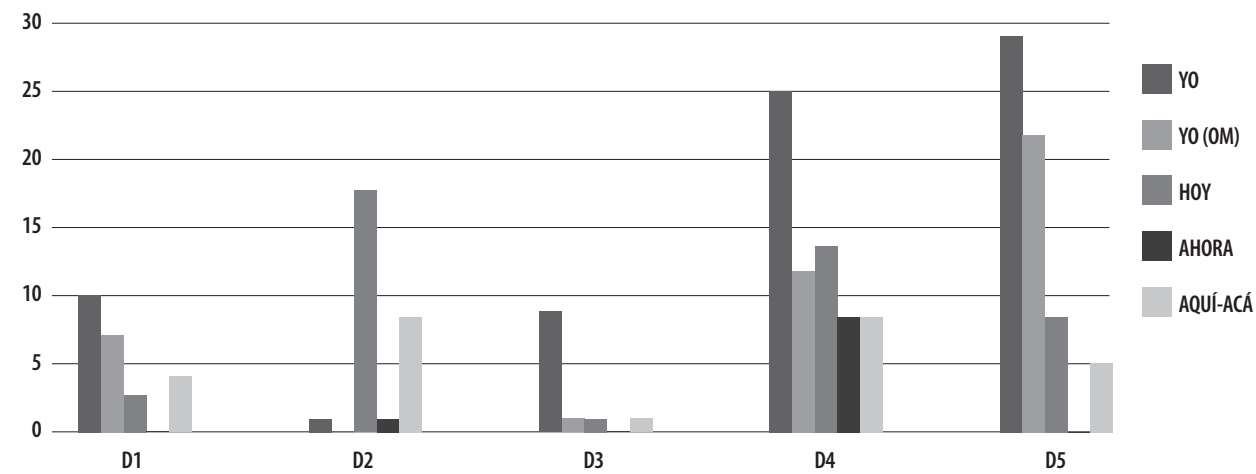

D2: el HOY (demarcación), tiene otras exigencias que el pasado D4-D5: alto grado de subjetividad luego de alcanzar el poder

Figura 8. Frecuencias en el sistema persona-espacio-tiempo en los cinco discursos. 
Una vez adquirido el poder nacional, Mujica claramente incrementa la referencia a sí mismo, como se comprueba en los últimos dos discursos, aunque la estrategia discursiva en ambas disertaciones varía, ya que en $\mathrm{D} 4$ el enunciador utiliza "me" y "mi", mientras que en D5 hace un uso explicito del "yo".

La cosmovisión que tiene Mujica podría ser el motivo por el cual se observa una alta frecuencia en el conjunto de discursos del "nosotros" como forma integradora de carácter multirreferencial. Por ende, se concluye que la mayor presencia de la primera persona del plural es la estrategia preferida por el enunciador.

Si con la forma de la primera persona del plural el enunciador implica totalmente a su auditorio, con la segunda persona del plural obtiene el efecto contrario al producir un distanciamiento. Mujica se aleja de sus oyentes concibiéndolos como un grupo diferenciado de sí mismo. Comparativamente la designación del destinatario mediante la segunda persona del plural es mucho más escasa que la que hace mediante la primera al servicio de una intención integradora evidente.

Como sujeto de la enunciación, Mujica opta por: 1) un discurso objetivo en el que intenta borrar sus huellas, y 2) un discurso subjetivo que contiene evaluativos implícitos y explícitos (con palabras portadoras de un rasgo semántico subjetivo) y representaciones colectivas (con las que valoriza o desvaloriza a los uruguayos).

\subsection{Análisis interdiscursivo}

El primer ejercicio de lectura del corpus consistió en el relevamiento de las marcas subjetivas que dejó Mujica en sus enunciados, las cuales se compilaron en

Tabla 4. Las personas del discurso (formas y frecuencias).

\begin{tabular}{lccccc}
\hline Forma & Discurso 1 & Discurso 2 & Discurso 3 & Discurso 4 & Discurso 5 \\
\hline Yo & 10 & 1 & 8 & 25 & 28 \\
\hline Yo (omitido) & 9 & 0 & 1 & 11 & 21 \\
\hline Nosotros & 37 & 55 & 18 & 54 & 33 \\
\hline Nosotros (om) & 70 & 65 & 19 & 73 & 25 \\
\hline Tú/ vos & 1 & 3 & 4 & 0 & 4 \\
\hline Ustedes & 12 & 1 & 6 & 7 & 7 \\
\hline El/ ellos & 3 & 12 & 5 & 4 & 4 \\
\hline
\end{tabular}


planillas separadas y cuya aplicación posteriormente se realizó en un ejercicio de relevamiento de enunciados paradigmáticos. Los seis enunciados paradigmáticos que se señalan a continuación para cada discurso sostienen el relato de Mujica por cuanto sintetizan sus grandes ideas como enunciador y constituyen los puntos de referencia de su modelo de pensamiento y de su interpretación de la realidad:

Cosmovisión, estrategia y unidad: los generadores de su relato.

Doctrina de acción y filosofía del Hombre Nuevo: las fuentes de legitimidad que utiliza para nutrir su relato (o núcleo invariante de creencias).

Ética activa y dialéctica: sus valores éticos individuales que le permiten mantener la coherencia de su relato en el tiempo.

Democracia y participación: cómo hace progresar su relato en el tiempo.

Cambio del sistema bipartidario uruguayo y redistribución del poder: el propósito final del relato y su prolongación en el tiempo.

Alteridad y/o adversario: cómo modifica o adapta el relato según sea la alteridad del alocutario (simpatizante, adversario, indiferente).

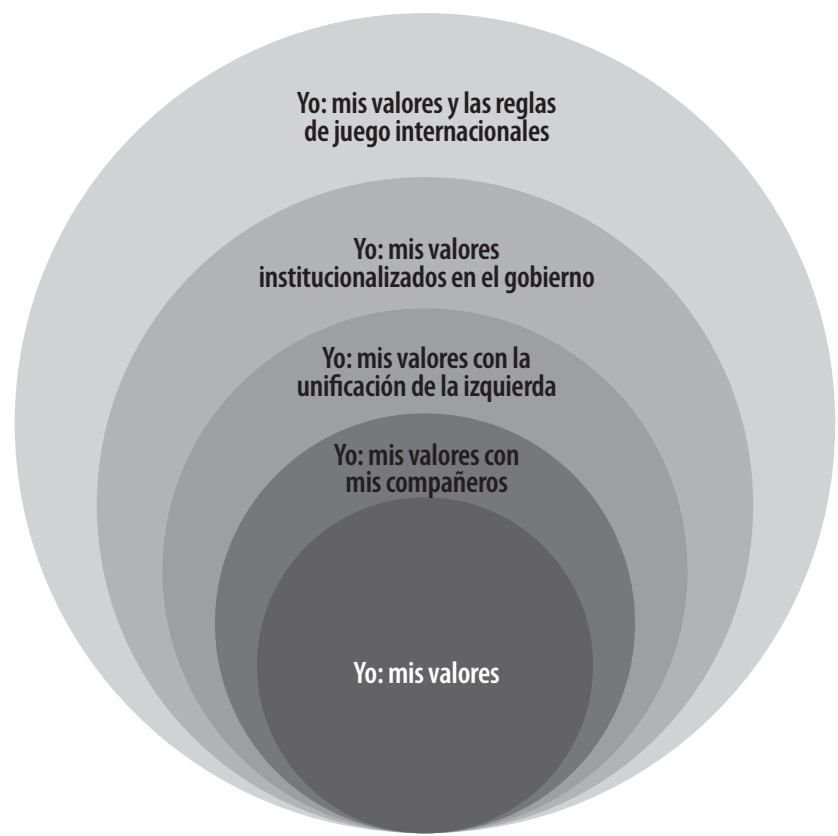

Figura 9. La persuasión construida desde la subjetividad y el núcleo de valores del Yo. 
Por ello los grandes ejes de significado que utiliza en sus enunciados incluyen la necesaria participación política de los que se sienten marginados u olvidados por el bipartidismo tradicional, una justa repartición del poder que los incluya, una ética activa en la vida pública, la unidad nacional y la aceptación de las contradicciones y paradojas del comportamiento social y político del país. En todos sus discursos se percibe un subtexto o guión invisible que une sus estrategias discursivas y que contienen una valoración moral, un discurso intersubjetivo de lenguaje popular, un basamento filosófico de ideales y un llamado a la acción.

Mediante un análisis discursivo diacrónico se cree haber identificado la evolución de sus palabras-lengua-discurso y se observa una continuidad en los temas filosóficos que constituyen sus seis grandes enunciados paradigmáticos. Desde una plataforma filosófica que podría calificarse de panteísta, un núcleo invariante de valores y utilizando su oralidad, Mujica logra plantar en la mente de sus oyentes una cosmovisión, un marco o paradigma para interpretar el mundo, sean estos sus compañeros militantes de antaño, sus camaradas de la izquierda uruguaya, todos los ciudadanos uruguayos o los grupos económicos internacionales con intereses presentes y futuros en el país (fig. 9).

Para lograr el objetivo de transferir su cosmovisión a estos círculos cada vez más amplios de alocutarios receptores de su relato, Mujica construye una imagen de sí mismo, siguiendo intuitivamente una formulación teórica: el enunciador es una imagen que crea el emisor del discurso. Esta construcción evoca la noción de Riorda donde el mito se forma tanto de la imagen como de una percepción social, como de la identidad.

\section{Conclusiones}

\section{Conclusión 1}

El primer objetivo fue estudiar el campo discursivo del presidente y comprobar si construía su propio relato o si surgía de las tradiciones del pueblo uruguayo tal como él lo interpreta. La conclusión preliminar es que Mujica toma del ethos uruguayo las idiosincrasias culturales y morales propias del pueblo y las reinterpreta exitosamente. Su estilo de comunicación es eficaz puesto que sus oyentes descodifican algo que les suena familiar y con lo que están plenamente de acuerdo.

Es interesante la evaluación que realiza Alain Labrousse (2009, p. 297-298) al constatar que lo que interesa observar no es solo el lenguaje propio de Mujica, sino que resultan aún más críticos y reveladores los simbolismos que crea para su acción 
comunicativa. El autor recoge en una entrevista la opinión de Juan Angel Urruzola, que perteneció a la columna revolucionaria bajo la dirigencia de Mujica, quien destaca los talentos de comunicador de Mujica: "Ese entrar a los temas desde otra percepción que la gran mayoría. Para mí ese es el quid de la cuestión de por qué Mujica hace un discurso diferente, corrido". El análisis confirma esta relación simbiótica entre el relato que construye y la esencia (valores, creencias, tradiciones) del pueblo uruguayo, y de que tal relato es una interpretación hiperrealista (como la de un pintor). Según afirma Adolfo Garcé2 en las entrevistas que le formuló Labrousse (2009), es el viejo lenguaje tupamaro del MLN reciclado para las nuevas circunstancias políticas, lo que significaría que el carácter épico del lenguaje revolucionario nunca fue abandonado por el presidente, sino simplemente readaptado a las nuevas circunstancias. Labrousse indica que ya en 1970 Mujica era conocido por sus "extraordinarios talentos de comunicador" y "personalidad excepcional". En lo que concierne a la construcción de consenso, este mismo autor cita a Garcé: "Mujica siempre es un gran articulador. El Rey de la articulación. [...] Tiene una enorme capacidad para componer, para dialogar, para negociar con todo el mundo. Pero muy propia de la cultura del MLN, que siempre fue una cultura muy plural en la interna y donde siempre hubo mucha negociación entre distintas visiones [...]". Los hallazgos de esta investigación demostraron que Mujica construye su relato alrededor de un núcleo invariante de valores, como lo define Verón, y de un mito político movilizador según el concepto de Riorda.

En las observaciones iniciales se señalaba que Mujica no solo habla como un uruguayo más, sino que utiliza en sus discursos métodos de convencimiento muy propios de su pueblo. La mejor muestra se verificó durante la campaña de las elecciones internas del Frente Amplio para elegir al candidato presidencial. Mientras el claro candidato favorito de la izquierda educada y urbana era Danilo Astori, la estrategia de Mujica de que "no podría ser candidato" aplicada mediante una descalificación de sí mismo ("tengo un aspecto lamentable, parezco un verdulero, estoy viejo y cansado, no tengo formación universitaria, etc.") fue precisamente una manera muy uruguaya de comunicarse subliminalmente con el pueblo. Además, la empatía que exhibe como persona sencilla y humilde le da carácter masivo a su campo discursivo; mediante un estilo coherente demuestra entender a la gente, se identifica con ella, piensa como ella y dice querer lo que la gente quiere. Resulta importante resaltar aquí la idea de Maingueneau de que "el ethos envuelve la enunciación". El ethos uruguayo forma parte intrínseca de la identidad que Mujica construye de sí mismo.

26 Las entrevistas se realizaron en junio de 2007 y marzo de 2009. 
La manifestación de la subjetividad en su campo enunciativo demuestra además su estrategia subyacente para consolidar el poder mediante la construcción de un relato coherente y perdurable en el tiempo. Resulta evidente el estrecho vínculo que hay entre el relato y la construcción del poder. Desde sus inicios en la militancia política, Mujica siempre predicó sobre la necesidad de cambiar el escenario político en el Uruguay caracterizado por un sistema bipartidario. Este objetivo subyace en su campo discursivo y constituye uno de los pilares centrales de su marco ideológico o Weltanschauung, además de acompañar a los núcleos invariantes del contenido de sus discursos. Mediante la legitimación de su identidad como líder y construyendo la confianza de sus audiencias al reforzar ciertos valores centrales, pudo afianzar la credibilidad de sus seguidores y votantes y construir poder:

1. La tradición oral tupamara, producto de la clandestinidad y el encarcelamiento, fortaleció en Mujica el don del relato, característica que también se encuentra en otros dirigentes políticos que sufrieron prisión y debieron ejercitar la memoria para subsistir ${ }^{27}$.

2. Los valores de Mujica no cambian y tiene la capacidad de codificarlos para su transmisión en cada situación comunicativa y descodificarlos para su comprensión para cada audiencia a medida que va ampliando la esfera de persuasión.

3. Mujica construye su legitimidad, por un lado, cambiando el campo semántico y transformándolo desde un inicial léxico revolucionario a otro socialista democrático y culminando en un léxico ético de carácter universal para llegar a una cantidad mayor de personas, y produciendo una ampliación pragmática del "nosotros inclusivo".

4. El discurso político es intersubjetivo y, por ende, implica la subjetividad de su enunciador, porque:

- no es solo polémico y necesita de un adversario. Se comprobó que puede manifestarse de otra manera (ejemplo: el enemigo abstracto de Schmitt), sea a partir de la alteridad como noción filosófica o frente a estructuras como lo hace Mujica; y porque - el enunciador realiza negociaciones, codificaciones y descodificaciones pertinentes a la situación de comunicación, recurriendo a la intersubjetividad para

\footnotetext{
27 Mandela, N. (2010, p. 148). Conversations with myself. Londres: Macmillan: "Estar solo en una prisión es una dificultad. Nunca lo pruebes. Lo que en realidad hicieron conmigo fue aislarme, sin castigarme en el sentido de privarme de alimentos. Pero se aseguraron de que no le viera la cara a otro prisionero. A propósito, descubrirías que la celda es un lugar ideal para aprender de tí mismo, para indagar realística y regularmente los procesos de tu mente y tus sentimientos. Aunque más no sea, la celda te da al menos la oportunidad de mirar integralmente tu conducta todos los días, de superar lo que tienes de malo y desarrollar lo bueno". Traducción propia.
} 
crear adhesión y consenso, constituyendo un proceso retroalimentado y una dialéctica intersubjetiva.

El estudio de la subjetividad en su campo discursivo indica que la idea de sí mismo está fuertemente ligada a su idea de la identidad colectiva uruguaya y que la persona Mujica difícilmente se pueda distinguir de la ideología del dirigente Mujica; es decir que al estudiar la subjetividad se observa que la expresión del "yo" se funde en un "nosotros colectivo" y que existe una estrecha identificación de Mujica con el pueblo. De ello se deriva que pareciera existir una estrecha correlación entre subjetividad y poder, aunque no se logró percibir la naturaleza de ese vínculo:

1. La subjetividad en el discurso político está estrechamente ligada a la construcción del poder.

2. Las marcas de la subjetividad se transforman o modifican una vez conseguido el poder.

3. El núcleo invariante de valores del enunciador es coherente con la imagen que construyó de sí mismo.

Detrás de sus palabras hay un sólido hilo conductor que hace que la coherencia de sus mensajes permanezca. Parte de la coherencia en su relato tiene que ver con el desarrollo de un pensamiento dialéctico que busca soluciones mediante las dicotomías propias de la vida natural - la aplicación de la autocrítica requerida del concepto revolucionario del Hombre Nuevo- y en su capacidad instintiva de construir el poder poco a poco, pausadamente. Mujica no cree en grandes cambios revolucionarios sino en transformaciones incrementales ${ }^{28}$ certeras.

\section{Conclusión 2}

Con respecto del propósito de indagar la validez de un modelo de análisis del discurso para estudiar la comunicación política en el Uruguay, se concluyó que se requiere mayor investigación para lograr un sólido marco teórico, mejores metodologías de trabajo y formas de captación de datos.

\section{Respecto del marco teórico}

1. La teoría de la enunciación de Kerbrat-Orecchioni que utilizamos es insuficiente para el análisis del discurso político por cuanto solo examina la subjetividad y no

\footnotetext{
28 El uso de este concepto también remite al pensamiento de Mario Riorda cuando desarrolla la acción incremental en su contribución sobre un modelo de comunicación gubernamental para el consenso.
} 
organiza la enunciación del lado en que la enfoca Verón en las múltiples destinaciones, ni explica cómo se construye el poder, que en nuestro caso remediamos con la teoría de comunicación de Riorda sobre el mito de gobierno. Como Mujica no utiliza la noción de adversario tal como la concibe Verón, es más apropiado el concepto de enemigo abstracto de Carl Schmitt utilizado en ciencia política, ya que opta en su estrategia discursiva por una alteridad abstracta o filosófica en vez de un contrincante real.

2. Hay otras categorías léxicas de la clasificación de la subjetividad que no fueron incorporadas por Kerbrat-Orecchioni en su obra que, en el particular caso del discurso político, resultan pertinentes de utilización. Entre ellas identificamos fórmulas tales como "tener que" o perífrasis modal de obligación "hay que" que apelan a lo deontológico o al deber. Quizás se relacionen con uno de los cuatro componentes de Verón (1987, p. 21), el componente prescriptivo referido a aquellas enunciaciones dentro del discurso político que son de orden del deber o lo deontológico.

\section{Respecto de la metodología}

1. Una metodología general de análisis del discurso político más refinada requeriría de un macroesquema teórico que determine los límites (al estilo Riorda), un esquema intermedio que categorice su contenido (al estilo Verón) y un microesquema que examine los enunciados en su situación de comunicación (al estilo Kerbrat-Oreccchioni).

2. El criterio de seguridad obliga a buscar hitos críticos en la historia del personaje político-enunciador que constituyan umbrales definitorios de etapas distintas. En esta investigación sirvieron para identificar los momentos de ruptura y crecimiento del enunciador Mujica en su trayectoria, y para marcar y visualizar la estructura del poder.

3. El relevamiento de deícticos y subjetivemas en Kerbrat-Orecchioni tuvieron que ser ampliados con otras nociones metodológicas para analizar los enunciados paradigmáticos y estrategias discursivas del presidente. Estas ampliaciones consistieron en un análisis cuantitativo de frecuencias de deícticos, la organización visual de las múltiples destinaciones en tres columnas (otro positivo, otro negativo y tercer hombre), la confección de una tabla de cómo el enunciador construyó su imagen en el corpus, el análisis de la verosimilitud de los actores en el guión del relato político, el inventario lexicológico de usos frecuentes que realiza Mujica, la confección visual de la evolución de los estadios, crecientes o decrecientes, de su poder político. 


\section{Respecto de los datos}

1. En ausencia de instrucciones para la aplicación de su modelo, fue necesario construir tablas clasificatorias propias con los conceptos de Kerbrat-Orecchioni para diseñar las planillas que relevaran los deícticos y subjetivemas en los discursos de Mujica. Este ejercicio fue productivo ya que la enorme cantidad de datos hubieran dificultado su realización con otro método de trabajo, salvo que se hubiera utilizado Atlas TI u otra herramienta similar de procesamiento de grandes cantidades de datos.

2. Para el análisis de datos es más conveniente utilizar de entrada los sintagmas nominales o enunciados compuestos por varias palabras por concentrar una mayor densidad de subjetividad que el uso de unidades léxicas subjetivas aisladas.

A lo largo de este artículo se describió y se analizó la coherencia discursiva del presidente Mujica, investigación focalizada en un personaje político de gran influencia en la lucha democrática por el poder en el Uruguay.

El estudio del caso puede verse, entonces, como un paso inicial y tentativo para la replicabilidad a otros corpus de discursos políticos al confirmar el modelo de análisis utilizado que se pueden descubrir elementos subyacentes en el campo discursivo de actores políticos.

\section{Referencias}

Aldrighi, C. (2001). La izquierda armada: ideología, ética e identidad en el MLN-Tupamaros. Montevideo: Ediciones Trilce.

Aldrighi, C. (2009). Memorias de insurgencia: historias de vida y militancia en el MLN-Tupamaros, 1965-1975. Montevideo: Ediciones de la Banda Oriental.

Benveniste, E. (1971). Problemas de lingüística general I. México: Siglo Veintiuno Editores.

Benveniste, É. (1977). Problemas de lingüística general II. México: Siglo Veintiuno Editores.

Blixen, S. (2009). El sueño del Pepe: José Mujica y el Uruguay del futuro. Montevideo: Ediciones Trilce. Caetano, G. (2011). La república batllista. 3a. ed. Montevideo: Ediciones de la Banda Oriental.

Campodónico, M. A. (2005). Mujica. Montevideo: Fin de Siglo.

Charaudeau, P. \& Maingueneau, D. (2005). Diccionario de análisis del discurso. Buenos Aires: Amorrortu.

Cultelli, A. (2006). La revolución necesaria: contribución a la autocrítica del MLN Tupamaros. Buenos Aires: Colihue.

De Giorgi, A. (2011). Tribus de izquierda: bolches, latas y tupas en los 60. Montevideo: Fin de Siglo.

Demasi, C.; Marchesi, A.; Markarian, V.; Rico, A. \& Yaffé, A. (2009). La dictadura cívico-militar: Uruguay 19731985. Montevideo: Ediciones de la Banda Oriental; Centro de Estudios Interdisciplinarios Uruguayos.

Ducrot, O. \& Todorov, T. (2011). Diccionario enciclopédico de las ciencias del lenguaje. Buenos Aires: Siglo Veintiuno.

Elizalde, L.; Fernández Pedemonte, D. \& Riorda, M. (2006). La construcción del consenso: gestión de la comunicación gubernamental. Buenos Aires: La Crujía Ediciones. 
Fernández Huidobro, E. (2012). Historia de los tupamaros. Montevideo: Ediciones de la Banda Oriental. Garcé, A. (2009). Donde hubo fuego: el proceso de adaptación del MLN-Tupamaros a la legalidad y a la competencia electoral, 1985-2004. 4a. ed. Montevideo: Fin de Siglo.

García, A. (2009). Pepe coloquios. Montevideo: Fin de Siglo.

García Negroni, M. M. \& Zoppi Fontana, M. (1992). Análisis lingüístico y discurso político: el poder de enunciar. Buenos Aires: Centro Editor de América Latina.

Gatto, H. (2000). El cielo por asalto: el movimiento de liberación nacional (tupamaros) y la izquierda uruguaya, 1963-1972. Montevideo: Taurus.

Gilio, M. E. (2011). Pepe Mujica: de tupamaro a presidente. Buenos Aires: Capital Intelectual.

Guevara, E. (2007). El socialismo y el hombre nuevo. Buenos Aires: Siglo XXI Editores. (Colección América nuestra).

Israel, S. (2014). Pepe Mujica el presidente: una investigación no autorizada. Montevideo: Planeta.

Kerbrat-Orecchioni, C. (1980). La enunciación: de la subjetividad en el lenguaje. 3a. ed. Buenos Aires: Edicial.

Kerbrat-Orecchioni, C. (1997). Lénonciation: de la subjetivité dans le langage. Paris: Armand Colin.

Kristeva, J. (2001). Semiótica 1. 4a. ed. Madrid: Fundamentos.

Labrousse, A. (2009). Una historia de los tupamaros: de Sendic a Mujica. Montevideo: Fin de Siglo.

Maingueneau, D. (2002). Problèmes d'éthos. Pratiques, 113-114.

Mazzeo, M. (2002). Charlando con Pepe Mujica. Montevideo: Ediciones Trilce.

Panizza, F. (1990). Uruguay: batllismo y después: Pacheco, militares y tupamaros en la crisis del Uruguay batllista. Montevideo: Ediciones la Banda Oriental.

Perelli, C. \& Rial, J. (1986). De mitos y memorias políticas: la represión, el miedo y después... Montevideo: Ediciones de la Banda Oriental.

Pernas, W. (2013). Comandante Facundo: el revolucionario Pepe Mujica. Montevideo: Santillana.

Rabuffetti, M. (2014). La revolución tranquila. Montevideo: Penguin Random House.

Rey Tristán, E. (2006). A la vuelta de la esquina: la izquierda revolucionaria uruguaya, 1955-1973. Montevideo: Fin de Siglo.

Riorda, M. (2006). Hacia un modelo de comunicación gubernamental para el consenso. En: Elizalde, L.; Fernández Pedemonte, D. \& Riorda, M. (eds.). La construcción del consenso: gestión de la comunicación gubernamental. Buenos Aires: La Crujía Ediciones.

Vasilachis de Gialdino, I. (coord.) (2006). Estrategias de investigación cualitativa. Buenos Aires: Gedisa.

Verón, E. (1987). La palabra adversativa: observaciones sobre la enunciación política. En: Verón, E.; Arfuch, L.; Chirico, M. M. et al. El discurso político: lenguajes y acontecimiento. Buenos Aires: Hachette.

Zanotti, G. (2005). Hacia una hermenéutica realista: ensayo sobre una convergencia entre Santo Tomás, Husserl, los horizontes y la ciencia y el lenguaje. Buenos Aires: Universidad Austral.

\section{Contacto}

\section{Monique Marie Vaughan Moppett}

monique_202@yahoo.com 